\title{
Nisin Probiotic Prevents Periodontal Disease and Inflammation while Promoting Periodontal Regeneration and a Shift Toward a Healthy Microbiome/Virome
}

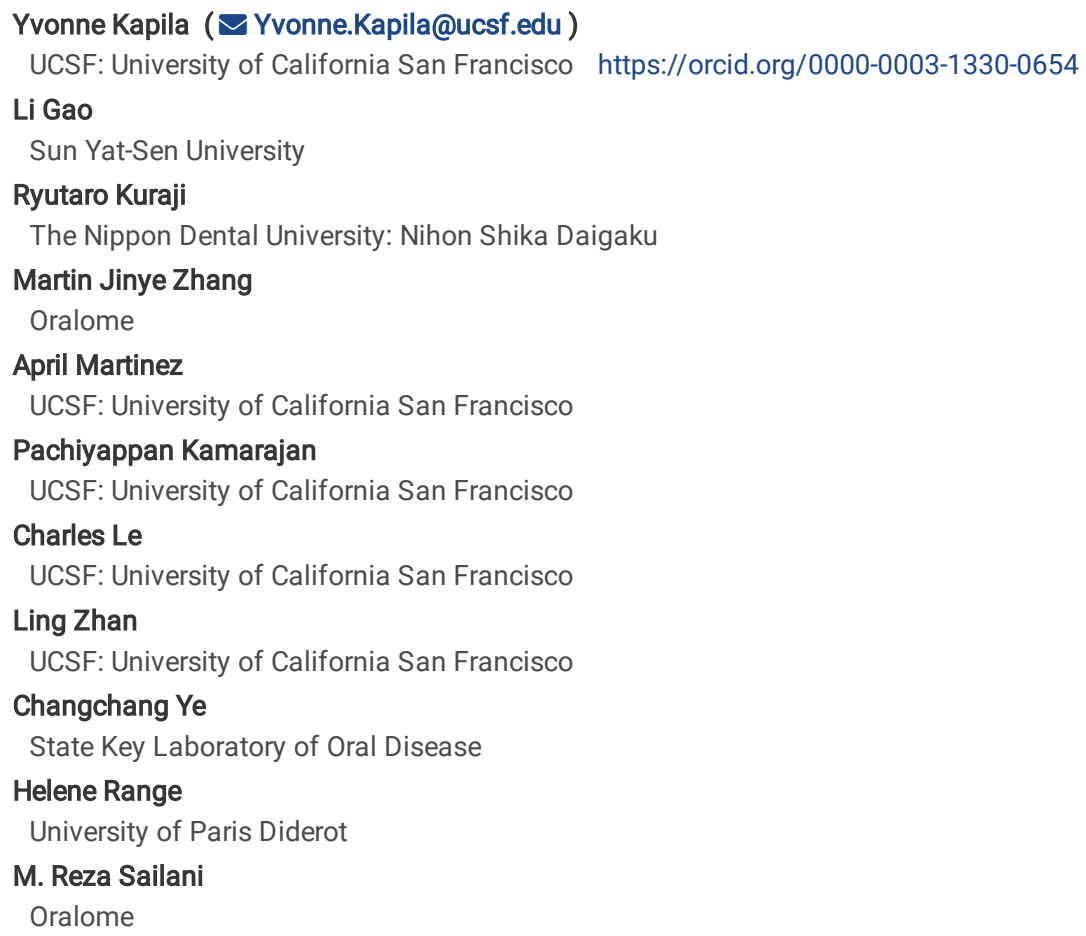




\section{Abstract}

Background

Dysbiosis of the oral microbiome mediates chronic periodontal disease, including its characteristic bone loss and host inflammatory response. Realignment of this microbial dysbiosis towards health may prevent disease. Treatment with antibiotics and probiotics can modulate the microbial, immunological, and clinical landscape of periodontal disease with some success. Antibacterial peptides or bacteriocins, such as nisin, and nisin-producing probiotics, Lactococcus lactis, have not been examined in this context, yet warrant further examination because of their biomedical benefits in eradicating biofilms and oral pathogenic bacteria, and modulation of immune mechanisms. The goal of this study was to examine the potential for nisin and a nisin-producing probiotic to abrogate periodontal bone loss and related inflammatory landscape while modulating the composition of the oral microbiome.

Results

A polymicrobial mouse model of periodontal disease was employed for this purpose. In a disease context, nisin and the nisin-producing Lactococcus lactis probiotic significantly decreased the levels of periodontal pathogens, alveolar bone loss, oral inflammatory host response, and host-antibody response to these pathogens. Surprisingly, nisin and/or the nisin-producing L. lactis probiotic also enhanced the number of gingival fibroblasts, periodontal ligament cells, and bone lining cells in response to the polymicrobial infection. Nisin and probiotic treatment significantly shifted the oral bacteriome and virome towards the healthy control state. This shift was characterized by a unique signature; health was associated with a Proteobacteria (Marinobacter sp. B9-2), whereas 3 retroviruses (Golden Hamster Intracisternal A-particle H18, Bat gammaretrovirus, and Porcine type C oncovirus) were associated with disease. Specific disease-associated microbial species were highly correlated with IL-6 levels.

Conclusions

Nisin's ability to shift the oral microbiome towards health, mitigate oral disease and the host immune response, and promote a novel regenerative periodontal phenotype, addresses key aspects of the pathogenesis of the disease. These benefits may negate the systemic effects associated with periodontal disease and reveal a new biomedical application for nisin in regenerative medicine.

\section{Background}

Periodontitis, a chronic inflammatory disease of the hard and soft tissues that support teeth, leads to alveolar bone destruction and tooth loss. Periodontal disease is prevalent both in developed and developing countries and affects about $40-50 \%$ of the global population, making it a high public health concern[1, 2]. It is associated with several systemic diseases, such as diabetes mellitus, cardiovascular diseases, adverse pregnancy outcomes, rheumatoid arthritis respiratory infections, Alzheimer's disease, and cancer[3-6]. A dysbiotic oral microbiota is the initiating factor in the etiology of periodontitis, which leads to a dysregulated host immune response[7, 8]. These dysbiotic oral microbes live in oral biofilms.

Oral biofilms are microbial communities with increased resistance to antimicrobial agents and elevated levels of virulence factors compared with planktonic bacteria $[9,10]$. Socransky[11] defined several microbial complexes in subgingival plaque biofilms according to their relationship to periodontal disease. Porphyromonas gingivalis, Treponema denticola, and Tannerella forsythia form the tightly related group known as the "Red Complex". Fusobacterium nucleatum, an important "microbial bridge" during dental plaque formation[10,11], belongs to the "orange complex" and is closely related to the red complex. Although novel sequencing methods are beginning to reveal other important microbes associated with periodontal disease[12], these four pathogens not only contribute to periodontal disease via a variety of mechanisms, but they also invade other organs and tissues[13], induce systemic infection, and play roles in the pathogenesis of cancers, cardiovascular diseases, metabolic diseases, and Alzheimer's disease[6, 14-17]. Therefore, controlling periodontal pathogens and maintaining a healthy oral biofilm is important in addressing the global burden of periodontal disease.

Scaling and root planing (SRP) is the gold standard for treatment of periodontitis, which is effective in removing plaque and reducing the bacterial load. Although this therapy adequately lowers bacterial counts, recolonization is a major problem[18]. Considering the limitations of SRP, local and systemic antibiotic administration can help address these shortcomings. However, antibiotic therapy may trigger gastrointestinal side effects[19], bacterial resistance and allergic reactions $[20,21,22]$. For this reason, the administration of beneficial bacteria in the form of probiotics can be a valuable alternative in the treatment of periodontitis. According to the World Health Organization (2012), probiotics are defined as 'live microorganisms that, when administered in adequate amounts, confer a health benefit on the host'[23]. Recent publications have demonstrated the potential benefit of probiotic administration for reducing periodontopathogenic bacteria, regulating immune response, and improving the clinical signs of the disease, suggesting a promising role for probiotics in enhancing periodontal health[24-35].

The probiotic Lactococcus lactis produces one of the most widely used bacteriocins, known as nisin. Nisin, a lantibiotic, is the first and only bacteriocin approved for use in food preservation by the US Food and Drug Administration. It is used globally and approved by the WHO for the same application. Nisin also has potential as a therapeutic agent in medical, dental, and veterinary applications[36, 37]. Howell et al[38] found that nisin was effective in the reduction of plaque build-up and gingivitis in a beagle dog model. Cunha et al[39] also reported the potential role of nisin in the control of periodontal disease in dogs. Our published research[40,41] demonstrated that nisin effectively abrogates the growth of planktonic pathogenic bacteria and biofilm-encased bacteria associated with caries, periodontal disease, and persistent endodontic infections without inducing cytotoxicity to human oral cells. Nisin also resets pathogenic oral biofilms towards control/healthy levels in vitro[42]. Although oral delivery of nisin can alter the gut microbiota in mice[43], there is no research on the effect of L. lactis and nisin on the oral microbiome (bacteriome and virome) and there is limited knowledge on their effects on periodontal disease. Taken in aggregate, these data provide the basis for the current investigation. In this study, a polymicrobial mouse model of periodontal disease[12] was 
induced by oral infection with P. gingivalis, T. denticola, T. forsythia, and F. nucleatum, and employed to examine the effects of nisin and the nisin-producing probiotic L. lactis in abrogating periodontal bone loss and modulating the composition of the oral microbiome and inflammatory landscape.

\section{Methods}

\section{Periodontal bacteria and polymicrobial inoculum}

In this study, the following periodontal pathogens were tested, P. gingivalis FDC 381, T. denticola ATCC 35405, T. forsythia ATCC 43037, and $F$. nucleatum ATCC 10953. They were cultured anaerobically $\left(85 \% \mathrm{~N}_{2}, 10 \% \mathrm{H}_{2}, 5 \% \mathrm{CO}_{2}\right)$ at $37^{\circ} \mathrm{C}$ in an anaerobic chamber as described previously[12,83]. $P$. gingivalis and F. nucleatum were grown for 3 days on Tryptic Soy Broth (Becton Dickinson, Franklin Lakes, $\mathrm{NJ}$ ) containing $5 \mathrm{mg} / \mathrm{ml}$ yeast extract, $0.5 \mathrm{mg} / \mathrm{ml} \mathrm{L}$ cysteine hydrochloride, $5 \mu \mathrm{g} / \mathrm{ml}$ hemin, $1 \mu \mathrm{g} / \mathrm{ml}$ menadione and $5 \%$ FBS (Gibco Thermo Fisher Scientific, Waltham, MA). T. denticola was cultured in Oral Treponeme Enrichment Broth (OTEB) media (Anaerobe systems, Morgan Hill, CA) for 5 days. T. forsythia was grown in Tryptic Soy Broth containing 5 mg/ml yeast extract, $0.5 \mathrm{mg} / \mathrm{ml} \mathrm{L-cysteine} \mathrm{hydrochloride,} 5 \mu \mathrm{g} / \mathrm{ml}$ hemin, $1 \mu \mathrm{g} / \mathrm{ml}$ menadione, $10 \mu \mathrm{g} / \mathrm{ml}$ N-acetylmuramic acid (Sigma-Aldrich, St. Louis, MO), and $5 \%$ FBS (Gibco) for 7 days. Bacterial concentration was determined quantitatively and each organism was resuspended in phosphate-buffered saline (PBS) at $1 \times$ $10^{10}$ bacteria per $\mathrm{ml}$ for experimentation.

For the oral polymicrobial infection, $P$. gingivalis was mixed with an equal volume of $T$. denticola for 5 min. Subsequently, $T$. forsythia was added to the culture tubes containing $P$. gingivalis and T. denticola, and the bacteria were mixed gently for 1 min and allowed to interact for an additional 5 min. Lastly, $F$. nucleatum was added and mixed well with $P$. gingivalis, $T$. denticola, and $T$. forsythia. After $5 \mathrm{~min}$, the four bacterial consortium was mixed thoroughly with an equal volume of sterile $4 \%(\mathrm{w} / \mathrm{v})$ carboxymethyl cellulose (CMC; Sigma-Aldrich) in PBS, and this mixture was used for the oral gavage[12,83].

\section{Lactococcus lactis growth conditions}

Two L. lactis strains were used in this study; nisin-producing L. lactis (ATCC 11454) was obtained from ATCC and non-nisin producing L. lactis (NZ9800) was kindly provided by Dr. Paul Cotter, Head of the Food Biosciences Department in the Teagasc Food Research Center, Cork Institute of Technology, Ireland. $L$. lactis strains were grown in Brain Heart Infusion (BHI, Sigma-Aldrich) media overnight in a $37^{\circ} \mathrm{C}$ shaking incubator. The $\mathrm{L}$. lactis strains were then pelleted by centrifugation, resuspended in PBS to a concentration of $1 \times 1010 \mathrm{CFU} / \mathrm{ml}$, and mixed with an equal volume of sterile $4 \% \mathrm{CMC}$. This mixture was used for oral inoculation .

\section{Nisin preparation}

An ultra-pure (>95\%) food grade form of nisin Z (NisinZ ${ }^{\circledR}$ P) also referred to as nisin ZP was purchased from Handary (S.A., Brussels, Belgium), a primary manufacturer of nisin in the food industry. From here forward, nisin ZP will be referred to as nisin. The stock solution was prepared at a concentration of 600 or $200 \mu \mathrm{g} / \mathrm{ml}$ in sterile water, filter sterilized, and stored at $4 . \mathrm{C}$ for a maximum of 5 days for use in experiments. For oral treatment of mice, the nisin solution was mixed with an equal volume of sterile $4 \% \mathrm{CMC}$ to reach the final concentration ( $300 \mathrm{or} 100 \mu \mathrm{g} / \mathrm{ml}$ ).

\section{Infection and treatment of mice}

A total of 60 eight-week old BALB/cByJ female mice (The Jackson Laboratories, Bar Harbor, ME) were housed in microisolator plastic cages and randomly distributed into 10 groups (6 mice per group). The description of the experimental groups and infection and treatment protocols are shown in (Figure $1 \mathrm{~A}$ and B). The experimental protocols were approved by the Institutional Animal Care and Use Committee of the University of California, San Francisco (IACUC APPROVAL NUMBER: AN171564-01B). All the mice were given trimethoprim (0.17 mg per $\mathrm{ml})$ and sulfamethoxazole (0.87 $\mathrm{mg}$ per $\mathrm{mL})$ daily for $7 \mathrm{days}$ in the drinking water and their oral cavity was rinsed with $0.12 \%$ chlorhexidine gluconate (Peridex) mouth rinse to inhibit the native oral microbiota[12,14]. The polymicrobial inoculum (5×109 combined bacteria per ml; $1 \times 109$ cells in $0.2 \mathrm{ml}$ per mouse; $2.5 \times 108$ P. gingivalis, 2.5×108 T. denticola, 2.5×108 T. forsythia and $2.5 \times 108$ F. nucleatum) was administered topically in the morning for 4 consecutive days every week for a total of 8 weeks. Nisin (100 or 300 $\mu \mathrm{g} / \mathrm{ml}, 0.2 \mathrm{ml}$ per mouse) and L. lactis ( $5 \times 109$ bacteria per $\mathrm{ml} ; 1 \times 109$ cells in $0.2 \mathrm{ml}$ per mouse) were administered every day in the evening every week for a total of 8 weeks. A sterile $2 \% \mathrm{CMC}$ solution was administered as the control treatment.

Following 8 weeks of polymicrobial infection, oral swab samples were collected to evaluate the microbial status and to examine the effect of nisin on periodontal pathogens. The samples were collected from the oral cavity of the mice using a sterile micro sized cotton swab. The teeth and surrounding gingival tissue were swabbed and the cotton tip was immersed in 10:1 Tris-EDTA buffer immediately and stored at $-80^{\circ} \mathrm{C}$ until further processing for DNA isolation. Then mice were euthanized and the blood was collected for analysis of antibody response to the periodontal pathogens. The maxillae and mandibles were resected from each mouse for morphometric, histologic, immunologic, and sequencing analysis.

\section{DNA isolation from oral swabs, ethanol precipitation, and real time PCR to confirm bacterial infection}

DNA isolated from oral swabs was used to evaluate and confirm infection in the mice using methods described in our previous study[12]. In brief, DNA was isolated from the swabs and purified using the QIAamp® DNA Mini kit (Qiagen, Germantown, MD, USA). Ethanol precipitation of DNA was then performed to prepare the samples for subsequent real time polymerase chain reaction (PCR). Lastly, standard real-time PCR was used to quantify the periodontal pathogens in the oral swab samples.

\section{Morphometric analysis of periodontal alveolar bone loss}


After autoclaving and de-fleshing to remove all the soft tissues, the left maxillae and mandible from each mouse were immersed in $3 \%$ hydrogen peroxide overnight and then stained with 1\% methylene blue. Digital images of both buccal and lingual/palatal root surfaces of all molar teeth were captured under a stereo dissecting microscope (SMZ1000, Nikon) at the magnification shown in the images, then the line tool of Image $\mathrm{J}$ software (NIH Image) was used to measure the alveolar bone loss from the cementoenamel junction (CEJ) to alveolar bone crest (ABC). For bone loss measurements, the distance between $\mathrm{CEJ}$ and $A B C$ were measured from a total of 28 sites on the buccal and lingual/palatal surfaces of the molars ( 3 sites on the first molar, 2 sites on the second molar, and another 2 sites on the third molar) $[12,84,85]$. Two blinded examiners (experienced periodontists) performed all measurements twice at separate times. Both horizontal bone loss and intrabony defects were detected under the stereo dissecting microscope. The intrabony defects were marked as present or absent[12,14].

\section{Histopathological evaluation of periodontal inflammation and cellular content}

The right maxilla was resected from each mouse and immediately fixed in $4 \%$ paraformaldehyde for $24 \mathrm{~h}$, then decalcified with diethyl pyrocarbonate-treated $0.5 \mathrm{M}$ ethylenediaminetetraacetic acid $(\mathrm{pH} 8)$ for 28 days at room temperature. The decalcified specimens were then dehydrated and embedded in paraffin using a fully-enclosed tissue processor (ASP300S, Leica Biosystems, Buffalo Grove, IL, USA). The tissue blocks were cut into serial sections (4 $\mu$ m) parallel to the mesiodistal plane using a microtome, then sections were stained with Mayer's hematoxylin (Sigma-Aldrich, St. Louis, MO, USA) and eosin Y solution (Sigma-Aldrich) for assessment of inflammation. The sections were examined with a stereomicroscope.

The number of inflammatory cells (round-shaped nuclei) and gingival fibroblast (spindle-shaped nuclei) within a square field (100 $\times 100 \mu \mathrm{m})$ in connective tissue adjacent to the gingival epithelium between first and second molars were morphologically evaluated and counted in three tissue sections per mouse specimen ( $n=3$ per group). Similarly, the number of periodontal ligament (PDL) cells (spindle-shaped nuclei in the PDL space) and alveolar bone lining cells (cell nuclei on bone surface) were counted. All cell counts were averaged for each group, and data were expressed as the mean number of cells per $1.0 \mathrm{~mm}{ }^{2}$ of connective tissue in the maxillary specimens.

\section{PCR evaluation of immune cytokine profiles from gingival tissues}

The gingival tissue was treated overnight at $4{ }^{\circ} \mathrm{C}$ with RNA stabilization solution (RNAlater, Invitrogen) after tissue harvesting. Samples were powdered with a mortar and pestle under continuous liquid nitrogen, and total RNA was then isolated from each sample using the RNeasy mini Kit (QIAGEN). The purity and quantity of the RNA were evaluated using the NanoVue Plus spectrophotometer (Biochrom Ltd.). Subsequently, total RNA was synthesized into cDNA using the SuperScript VILO Master Mix (11755050; Invitrogen).

To assess the immune cytokine profiles in gingival tissues, relative gene expression was evaluated by real-time PCR as in our previous study[86] using the

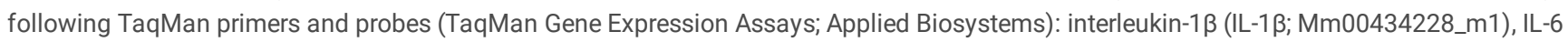
(Mm00446190_m1), tumor necrosis factor-a (TNF-a; Mm00443258_m1), interferon gamma (IFN-Y; Mm01168134_m1), C-C Motif Chemokine Ligand 2 (CCL2; Mm00441242_m1), C-X-C Motif Chemokine Ligand 2 (CXCL2; Mm00436450_m1), and transforming growth factor beta 1 (TGF- $\beta 1$; Mm01178820_m1). Glyceraldehyde 3-phosphate dehydrogenase (GAPDH; Mm99999915_g1) was used as a housekeeping gene to normalize the amount of mRNA present in each reaction. PCR was performed in $20 \mu \mathrm{l}$ reaction mixtures containing the TaqMan Fast Advanced Master Mix, cDNA template (20 ng/well), primers, and probes using a QuantStudio 3 Real Time PCR system (Thermo Fisher Scientific). The optimized thermal cycling conditions were as follows: 20 min at $95^{\circ} \mathrm{C}$, followed by 40 cycles per $1 \mathrm{~min}$ at $95^{\circ} \mathrm{C}$, and $20 \mathrm{~min}$ at $60^{\circ} \mathrm{C}$. To compare the expression levels among different samples, the relative expression level of the genes was calculated by the comparative CT $(\triangle \Delta \mathrm{CT})$ method using QuantStudioTM Design \& Analysis Software.

\section{Serum antibody analysis}

Serum from all 60 mice was collected on the day of euthanasia and used to determine the host response in the form of immunoglobulins (IgG) against $P$. gingivalis, T. denticola, T. forsythia, and F. nucleatum by an enzyme-linked immunosorbent assay (ELISA)[12,14]. For positive controls for the ELISA, each of these pathogens was grown to a cell density of $7 \times 108 \mathrm{cells} / \mathrm{mL}$ and harvested by centrifugation $\left(7000 \times \mathrm{g}, 30 \mathrm{~min}, 4^{\circ} \mathrm{C}\right)$. After washing, the cells were treated overnight with $0.5 \%$ formalin in buffered saline, then diluted to $0.3(0 D 600 \mathrm{~nm})$ in $0.05 \mathrm{M}$ carbonate-bicarbonate buffer and used as the coating antigen. The amounts of specific IgG antibodies present were determined by using a mouse IgG ELISA quantification kit (Bethyl Laboratories, USA). A pilot test was first performed with diluted (1:100) mouse serum to confirm reactivity with the bacterial antigens after $1 \mathrm{~h}$ at room temperature. Then, after coating with the formalin-fixed bacterial cells, wells were incubated with diluted mouse serum (1:100) for $1 \mathrm{~h}$ at room temperature. Wells were then washed with PBS containing $0.05 \%$ Tween-20 (PBST), and alkaline phosphatase-conjugated goat anti-mouse IgG and the 3,3',5,5'-tetramethylbenzidine chromogenic substrate reagent were added for detection and measurement of antibody response. Samples were assayed in duplicate and the purified mouse IgG was used to establish a standard curve on each plate for specific IgG quantification.

\section{DNA isolation from gingival tissue for next generation shotgun sequencing}

DNA was extracted from the mandibular gingival tissue of all mice (6 mice/group) using the QIAamp® DNA Mini kit (Qiagen, Germantown, MD, USA) as follow. The gingival tissue was ground in liquid nitrogen with a mortar and pestle and $180 \mu \mathrm{l}$ of Buffer ATL was mixed with 25 mg of tissue powder by vortexing. Then, $20 \mu \mathrm{l}$ of QIAGEN proteinase $\mathrm{K}$ was applied to each sample and samples were incubated at $56^{\circ} \mathrm{C}$ for 3 hours in a shaking water bath. Subsequently, $20 \mu \mathrm{l}$ of the RNase reagent $(20 \mathrm{mg} / \mathrm{ml})$ was added to the samples followed by incubation for 2 min at room temperature. After adding $200 \mu \mathrm{l}$ of Buffer AL, the samples were incubated at $70^{\circ} \mathrm{C}$ for $10 \mathrm{~min}$. In addition, $200 \mu \mathrm{l}$ of pure ethanol was mixed with each sample. This entire mixture was then applied into the QIAamp Mini spin column and centrifuged at $6000 \mathrm{xg}$ for $1 \mathrm{~min}$. Next, $500 \mu \mathrm{l}$ of Buffer AW1 were added to the spin column and samples centrifuged at $6000 \mathrm{x} \mathrm{g}$ for $1 \mathrm{~min}$. Then, $500 \mu \mathrm{l}$ of Buffer AW2 was added and samples were centrifuged at full speed $(20,000 \times \mathrm{g})$ for $3 \mathrm{~min}$, followed by centrifugation $(20,000 \times \mathrm{g})$ for 1 min again to eliminate the chance of possible Buffer AW2 carryover. Lastly, samples were incubated with $200 \mu \mathrm{ll}$ of Buffer AE 
in the spin column, which was placed in a clean $1.5 \mathrm{ml}$ microcentrifuge tube at room temperature for 5 min, then DNA were eluted by centrifugation at $6000 \mathrm{x}$ $\mathrm{g}$ for $1 \mathrm{~min}$.

The purity and quantity of the DNA were evaluated using the NanoDrop ${ }^{\mathrm{TM}}$ OneC Microvolume UV-Vis Spectrophotometer (Thermo Scientific), which met quality control measures for subsequent shotgun sequencing analysis.

\section{Metagenome shotgun sequencing and microbiome data production and analyses}

Shotgun metagenomic sequencing library preparation was performed by Novogen, Inc. The libraries were prepared according to a standard protocol from Illumina, and at least $1 \mathrm{~Gb}$ of 150 bp pair-end reads per sample were sequenced on the lllumina Hiseq4000 machines. FASTQ files were generated from the sequencing machines and used for the analyses of the bacteriome/microbiome and virome as described below.

\section{Data Processing}

The following criteria were used for processing and cleaning up the raw data. Low quality bases (Q-value $\leq 38$ ), which exceeded a certain threshold ( 40 bp by default) were trimmed. Reads which contained $\mathrm{N}$ nucleotides over a certain threshold (10 bp by default) were trimmed. Reads which overlapped with adapter over a certain threshold ( $15 \mathrm{bp}$ by default) were trimmed.

\section{Metagenome assembly}

We utilized de novo assembly for each sample as follows. Samples passing quality control were assembled initially using SOAPdenovo (http://soap.genomics.org.cn/soapdenovo.html). The Scaffolds were cut off at "N" to get fragments without "N", called Scaftigs. Clean data for all samples were then mapped to assembled Scaftigs using SoapAligner (http://soap.genomics.org.cn/soapaligner.html) and unutilized paired-end reads were collected. Mixed assembly was conducted on the unutilized reads with the same assembly parameter. The scaftigs of each sample and mixed assembly, which were less than $500 \mathrm{bp}$, were trimmed.

\section{Taxonomy annotation}

The following taxonomy annotation scheme was used. We aligned unigenes to the NCBI nonredundant database with DIAMOND to taxonomically annotate each metagenomic homolog (MEGAN). According to the abundance table of each taxonomic level, various analyses were performed using custom scripts by $\mathrm{R}$ and Python.

\section{Statistical analysis}

SPSS 21.0 statistical software (IBM, Chicago, IL, USA) was used for statistical analysis of the non-sequencing data. Student's t-test was used to compare two independent groups. For comparison of intrabony defects, data were expressed as frequency and percentage, and a chi-square test was used for analysis. Further, analyses of the PCR data from the oral swabs and quantification of inflammatory cells were performed using an ANOVA followed by a Tukey's test. Data were presented as means \pm standard deviations (SD). Values of $p<0.05$ were considered significant.

For the microbiome/virome analyses, we normalized the data to have 1 million reads per sample (reads per million, RPM). We filtered out taxa with average read counts less than 1 RPM. We removed 5 samples, namely Infection 1, Infection 6, Non-nisin L. lactis + Infection 4, Non-nisin L. lactis + Infection 6 and Nisin + Infection 3, that have low sequencing coverage. We used the Shannon diversity index to quantify bacterial and viral diversity across different groups. In order to compare the difference of bacterial contents, viral contents, and Shannon diversities between different groups, we computed the p-values using a twosample t-test assuming equal variance of samples from the two groups. For the Principal Coordinates Analysis (PCoA), we further restricted to species with RPM $<500$ to avoid the result being dominated by commonly present species. Three species, namely Mouse Intracisternal A-particle, Chlamydia abortus, Chlamydia trachomatis, were filtered out under this criterion. We used the Bray Curtis dissimilarity to quantify the difference between microbiome composition of different samples. The $95 \%$ confidence ellipses were computed assuming that the data in each group followed a two-dimensional normal distribution. For the differential abundance analysis, we performed a log transformation $(\log 10(\mathrm{RPM}+0.1))$ for the bacterial and viral read counts and used a two-sample ttest to compute the $\mathrm{p}$-values, assuming equal variance in the two groups. We further used the Benjamini-Hochberg procedure[87] to correct for multiple comparisons. We reported the corresponding false discovery rate (FDR) for conducting pair-wise comparisons (e.g., Infection versus Control), and the multiplicity is the total number of taxa. For correlating microbial species with the immune markers, we considered the data in log space for both read counts and immune marker measurements $(\log 10(x+0.1))$. We considered only microbial species that are significant in at least one differential abundance comparison (comparison v.s. control or v.s. infection). We computed Pearson's correlation with a p-value based on t-test. We performed the BenjaminiHochberg procedure ${ }^{88}$ for multiple testing for each immune marker (across all microbial species) separately.

\section{Results}

\section{Polymicrobial oral infection is reduced by nisin probiotic}

A PCR-based approach was used to evaluate the ability of nisin and a nisin-producing probiotic $L$. lactis to modulate oral infection by periodontal pathogens in a polymicrobial infection mouse model (Fig. 1A and B). Oral swab results indicated that all four bacteria were detectable at 8 weeks post infection (Fig. $2 \mathrm{~A}$ ). In the infection group, P. gingivalis, T. forsythia, and F. nucleatum were present at significantly higher levels than the control group ( $<<0.001)$. Similarly, $T$. denticola showed a trend toward higher levels in the infection group, but this was not significantly different from the control group. Treatment with nisin or the nisin-producing L. lactis probiotic markedly decreased the number of $P$. gingivalis, $T$. forsythia, and $F$. nucleatum compared to the infection group ( $\mathrm{p}<0.01$ ). In 
contrast, the non-nisin-producing probiotic group showed that $T$. forsythia and F. nucleatum didn't recover back to control levels; and these levels were significantly higher compared to the nisin-producing probiotic group $(p<0.05)$.

In addition, the frequency of mice exhibiting infection differed depending on the pathogens (Fig. 2B). P. gingivalis as well as T. forsythia and F. nucleatum were present in all mice in all groups, whereas $T$. denticola was present in much fewer mice across all groups.

\section{Alveolar bone loss parameters were significantly inhibited in mice treated with nisin or nisin probiotic}

A polymicrobial infection mouse model of periodontal disease was used to evaluate the ability of nisin and a nisin-producing probiotic $L$. lactis to modulate periodontal bone loss. After 8 weeks of inoculation/infection with periodontal pathogens ( $P$. gingivalis, T. denticola, T. forsythia and F. nucleatum), mice treated simultaneously with nisin or the nisin-producing probiotic L. lactis exhibited significantly less bone loss compared to the infection group (Fig. $3 \mathrm{~A}$ and B). Treatment with either high or low concentrations of nisin both showed significant rescue effects and significantly diminished bone loss in the presence of infection. The non-nisin producing $L$. lactis probiotic was unable to prevent the bone loss in the infected group.

The presence of alveolar intrabony defects were also evaluated following treatment. Nineteen percent of control uninfected sites showed a baseline level of intrabony defects compared to $58 \%$ of infected sites (Fig. 3C). Nisin (low or high concentrations) and the nisin-producing probiotic significantly decreased the number of sites that exhibited intrabony defects; $31 \%, 22 \%$, and $33 \%$, respectively. The non-nisin producing probiotic was unable to significantly prevent the development of intrabony defects; however the percentage of sites (49\%) that exhibited defects was lower than that of control infected sites (58\%). Although, the comparison between the Infection + L. lactis group (33\%) and Infection plus non-nisin L. lactis group (49\%) showed no significant difference (P >0.05), the Infection plus non-nisin L. lactis group exhibited higher numbers. However, the Infection plus L. lactis group was significantly different from the infection control group, but the Infection plus non-nisin L. lactis group was not.

\section{Host antibody response against periodontal pathogens is attenuated with nisin or nisin probiotic}

To evaluate the host response to the polymicrobial infection, serum antibody levels to the 4 periodontal pathogens were evaluated using an ELISA. Control infected mice showed a significant antibody response to all 4 periodontal pathogens compared to the uninfected control mice (Fig. 4). Nisin (low or high concentrations) and the nisin-producing probiotic significantly decreased the antibody response in the infected mice. The non-nisin producing $L$. lactis was also able to decrease the antibody response to the periodontal pathogens, however the effect was not as significant as that compared to the nisin-producing probiotic.

\section{Nisin or nisin probiotic prevent an influx of inflammatory cells into the periodontal complex upon polymicrobial infection}

To evaluate nisin's ability to alter the host inflammatory response in the context of periodontal disease, we evaluated the inflammatory cell infiltrate and morphologic changes within the periodontal tissues using hematoxylin and eosin staining of sagittal sections (Fig. 5A). In the control group, few inflammatory cells were observed in the gingival connective tissue just below the thin junctional epithelium. In contrast, the gingival tissues from the polymicrobial infection group exhibited an infiltration of numerous inflammatory cells $(p<0.001$; Fig. $5 B$ ) and deep periodontal pocket formation with epithelial hyperplasia and rete ridge elongation. Treatment with nisin and the nisin-producing probiotic $L$. lactis significantly decreased the inflammatory cell infiltrate in the infection group $(\mathrm{p}<0.001)$. However, treatment with the non-nisin-producing $L$. lactis did not significantly decrease the inflammation compared to the infection group.

\section{Nisin or nisin probiotic activate a proliferative phenotype in cells of the periodontium}

Surprisingly, nisin and/or the nisin-producing L. lactis probiotic also markedly increased the number of fibroblast-like and osteoblast cells (gingival fibroblasts, periodontal ligament cells, alveolar bone lining cells) compared to the control and/or infection groups ( $p<0.05$; Fig. 5B). In contrast, application of the nonnisin-producing L. lactis did not significantly increase the number of gingival fibroblasts or alveolar bone lining cells. This is the first time that nisin or a probiotic has been shown to promote the number of oral cells responsible for the regenerative potential of the periodontium.

\section{Nisin or nisin probiotic abrogates the host inflammatory cytokine response to the periodontal pathogens}

To further examine the effect of nisin or nisin probiotic on the host inflammatory response in the context of periodontal disease, the relative gene expression of inflammatory cytokines was assessed in gingival tissues by real-time PCR (Fig. 6). The infection group showed a significant upregulation of IL-1 $\beta$, IL-6, and CXCL2; the latter is homologues to IL-8 in mice $(p<0.05)$. However, treatment with nisin or the nisin-producing $L$. lactis probiotic significantly reduced their expression in the infected mice. The non-nisin producing $L$. lactis also suppressed the inflammatory response similar to the nisin- producing $L$. lactis, indicating that the $L$. lactis itself modulated the host inflammatory response. Other cytokines, namely TNF-a, IFN- $\gamma$, CCL2, and TGF- $\beta$, showed no significant changes following the polymicrobial infection or nisin treatment, although the anti-inflammatory cytokine TGF- $\beta$ showed a trend toward higher levels with nisin treatment.

\section{Nisin and the nisin probiotic promote a shift from a disease-associated microbiome toward a "healthy control" oral bacteriome and virome}

In order to assess how nisin and the nisin-producing probiotic modify the oral bacteriome and virome, and how it compares across infection and healthy groups, we conducted metagenome shotgun sequencing analysis of these different conditions. We compared the bacterial (Fig. 7A) and viral content (Fig. 7B) of groups treated with nisin, nisin-producing L. lactis probiotic, and non-nisin producing L. lactis with and without infection and compared against the control group and against the infection group. We observed significant differences in viral content across groups. However, we observed only minor differences in bacterial content. With regards to viral content for different groups, the infection group had significantly higher viral content than the control group (nominal $p$ value 0.041), nisin group (nominal p-value 0.032), infection plus nisin group (nominal p-value 0.0029), and infection plus $L$. lactis group (nominal $p$-value 0.0020). In concordance with the bacterial content, bacterial Shannon diversity for different groups showed no significant differences across groups (Fig. 7C). 
However, the viral diversity score was different across some groups. Specifically, the infection group was higher but not significantly different in diversity than the control group (nominal p-value 0.18) and L. lactis group (nominal p-value 0.16) (Fig. 7D).

To assess the overall change in the oral bacteriome and virome composition, we further performed Principal Coordinates Analysis (PCoA). As shown in Fig. 5A, we found that PC3 and PC4 separate the control group from the infection group (explained variance of $9.6 \%$ and $8.3 \%$, respectively. See also Supplementary Fig. 1 for the first 5 PCs). To investigate if the microbiome compositions of other groups were more similar to the control group or the infection group, we further overlaid each of the other groups on top of the control group and the infection group. Importantly, we found that among infected animals, those treated with nisin (Fig. 8B) and the nisin-producing L. lactis probiotic (Fig. 8C) were similar to the control group, indicating that nisin and L. lactis drive the microbiome composition toward the healthy state. In contrast, those treated with the non-nisin producing L. lactis (Fig. 8D) were in between the control and infection group, indicating that non-nisin producing $L$. lactis is less effective as a treatment in shifting the oral microbiome toward the healthy control. Other non-infection groups were more similar to the control group (nisin in Fig. 8E and L. lactis in Fig. 8F), except the non-nisin producing L. lactis group (Fig. 8G), which had a high variance.

Furthermore, we identified bacteria and viruses at the genus and species level that showed differences in abundance across groups. In this regard, in order to identify specific differences, we performed two different analyses; the first analysis was based on using the healthy control group as the reference group (Fig. 9A, B) and a second analysis was based on using the infection group as the reference group (Fig. 9C, D).

At the genus level and looking at differences relative to the control group, we observed that the genus Enterococcus was in lower abundance across different groups when compared against the control group (Fig. 9A). This was specifically observed in the infection plus $L$. lactis (FDR $<0.1)$ and non-nisin $L$. lactis groups (FDR < 0.3) (Fig. 9A). The infection plus nisin group also showed a lower abundance, although this did not reach statistical significance. In addition, the genus Marinobacter showed a reduced abundance in the infection group (FDR $<0.3)$ compared to the control. Moreover, the genus Pasteurella showed a reduced abundance in the infection plus $L$. lactis group (FDR $<0.1)$ compared to the control. Also, the genus Pseudomonas and genus Enterobacter showed an increased abundance compared to the control, specifically in the infection plus nisin (FDR < 0.2$)$ and infection plus non-nisin L. lactis (FDR < 0.3$)$ groups, respectively (Fig. 9A). The groups with the least change relative to the control group were the nisn and L. lactis groups.

At the species level and looking at differences relative to the control group (Fig. 9B), we observed that the Golden Hamster Intracisternal A-particle H18, Bat gammaretrovirus and Porcine type $C$ oncovirus showed increased abundance (FDR $<0.2)$ upon infection compared to the control group, suggesting their role in the disease process. However, Marinobacter sp. B9-2 showed a reduced abundance (FDR $<0.3)$ in the infection group compared to the control group, suggesting its role in health. In addition, both Enterococcus faecium and Pasteurella multocida showed a decreased abundance (FDR $<0.1)$ in the infection plus L. lactis group compared to the control group. The non-nisin producing L. lactis group showed a decreased abundance of Enterococcus faecium and an increased abundance of Golden Hamster Intracisternal A-particle H18 (FDR < 0.3) compared to the control group.

At the genus level and looking at differences relative to the infection group (Fig. 9C), we observed that the infection plus $L$. lactis group showed decreased abundances at the genius level for Salmonella (FDR $<0.2)$, Gammaretrovirus (FDR $<0.2)$, Intracisternal A-particles (FDR $<0.1)$ compared to the infection group. However, Betaretrovirus (FDR $<0.1)$ showed an increased abundance in the infection plus $L$. lactis group compared to the infection group. The infection plus nisin group also showed a decreased abundance in Gammaretrovirus (FDR $<0.2)$ and Intracisternal A-particles (FDR $<0.2)$ compared to the infection group. In addition, the genus Marinobacter showed a higher abundance across different treatment groups compared to the infection group, again suggesting a potential association with health.

At the species level and looking at differences relative to the infection group (Fig. 9D), we also observed some microbes in higher abundance across different groups compared to the infection group (e.g. Marinobacter sp. B9-2 and Mouse mammary tumor virus); suggesting their potential involvement in maintaining health. In contrast, Mouse intracisternal A-particle, Bat-gammaretrovirus, Golden hamster intracisternal A-particle H18, Salmonella enterica and Porcine type-C oncovirus were in lower abundance across different groups compared to the infection group, suggesting their potential involvement in the transition to disease (Fig. 9D).

\section{Specific microbial species (bacteria and viruses) are correlated with IL-6 levels}

We next examined potential correlations between microbial changes and cytokine levels across all groups. We identified significant correlations between specific microbial species (bacteria and viruses) and IL-6 levels (Fig. 9E and F). Specifically, s_Golden hamster intracisternal A-particle H18 (FDR < 0.1) exhibited the highest level of positive correlation with IL-6 levels. The following species also exhibited a positive correlation with IL-6 but at a decreased level of significance (FDR < 0.3): s_Bat gammaretrovirus, s_Salmonella enterica, and s_Porcine type-Concovirus. The following, s_Marinobacter sp.B9-2, was the only species showing a moderate negative correlation (FDR $<0.3)$ with IL-6 levels.

\section{Discussion}

Studies exploring the potential of probiotics to suppress periodontal pathogens or anaerobic bacteria in human and animal studies have shown some benefits. Human studies exploring probiotics as monotherapy or adjunctive therapy have shown some benefit or neutral effects in reducing periodontal pathogens or anaerobes with the probiotics Lactobacillus salivarius WB27[44], L. reuteri[18, 45, 46, 47], bacillus[48], L. plantarum[33], L. rhamnosus SP1[49], B. lactis[31] and various Streptococci[24, 32, 50]. Animal studies also showed some benefits. When Lactobacillus brevis or Bifidobacterium lactis were applied in a murine model of periodontitis, there was a significant decrease in the counts of anaerobic bacteria relative to aerobic bacteria[51, 52]. Use of Lactobacillus rhamnosus GG showed no antimicrobial activity against $P$. gingivalis and $F$. nucleatum[53]. The current investigation demonstrated that the nisin-producing probiotic and nisin itself reduced the oral levels of all the Red complex bacteria, P. gingivalis, T. forsythia, and T. denticola, and the orange complex pathogen, F. nucleatum, indicating nisin/nisin probiotic's efficacy in consistently removing these pathogens from oral surfaces.

Page $7 / 18$ 
Probiotic effects on periodontal bone loss have not been examined in humans, however, studies in animal models (dogs, rats, mice) have shown significant beneficial effects with use of various Streptococci species, Bacillus subtilis, Lactobacillus brevis, Saccharomyces cerevisiae, Bacillus subtilis, Bacillus licheniformis, Bifidobacterium animalis subsp. lactis, Bifidobacterium lactis, and Lactobacillus rhamnosus GG[24, 51-59]. In the current study, significant decreases in alveolar bone loss and intrabony defect formation were observed with the use of the nisin-producing Lactococcus lactis probiotic or nisin itself. Furthermore, low and high concentrations of nisin were equally effective at reducing bone loss.

Probiotics have not been examined for their potential to reduce the host systemic antibody response to periodontal pathogens in a periodontal setting in humans or animals[24]. The current investigation revealed that Lactococcus lactis probiotic or nisin itself can significantly reduce the systemic antibody response to all periodontal pathogens. This suggests that this nisin probiotic and nisin have significant potential for blocking the negative downstream systemic effects associated with these periodontal pathogens. It is noteworthy that the non-nisin producing L. lactis also mediated some beneficial effects. Some of the partial effects mediated by the non-nisin producing L. lactis control may be due to it is inherent properties as a lactic acid bacteria (low pH and enzymatic activity); which may contribute to its effects[34,60]. For example, the non-nisin producing probiotic was also able to decrease the antibody response to the periodontal pathogens, however the effect was not as significant as the nisin-producing L. lactis (Fig. 2D).

The host immune and extracellular matrix /bone turnover response to probiotics have been examined in humans and animal studies. In humans, Lactobacillus casei, Lactobacillus reuteri, and Lactobacillus brevis, reduced the levels of MMP-3, elastase, and cytokines and chemokines, including TNF-a, IL$8, I L-1 \beta, P G E_{2}[24,61-64]$ when used as monotherapy. When used as adjunctive therapy, the probiotics Lactobacillus reuteri and Bifidobacterium lactis reduced the levels of pro-inflammatory cytokines, including TNF-a, IL-1 $\beta$, IL-17, IL-8, increased the levels of anti-inflammatory cytokines, including IL-10, and improved the levels of ECM molecules (MMP-8 and TIMP-1)[26, 31, 65]. In animals (rodents), Lactobacillus brevis, Saccharomyces cerevisiae, Bacillus subtilis, Bacillus licheniformis, Lactobacillus casei subspecies pseudoplantarum, Lactobacillus casei subsp casei, Lactobacillus fermentum, Lactobacillus helveticus, and Bifidobacterium animalis subspecies lactis reduced the levels of pro-inflammatory cytokines, including TNF-a, IL-1 13 , IL-6, and IL-17A, increased the levels of anti-inflammatory cytokines, decreased the level of inflammatory cells and bone turnover markers, including C-terminal telopeptide, TRAP signal/TRAP positive osteoclasts, nuclear factor-KB ligand (RANKL)/osteoprotegerin (OPG) ratio[51, 52, 53, 56-59, 66]. Similarly, in the current study, the probiotic L. lactis and its nisin bacteriocin decreased both the number of oral inflammatory cells and the number of pro-inflammatory cytokines.

The novel discovery that nisin and the nisin-producing probiotic L. lactis promoted increases in the number of regenerative cells of the periodontium is surprising. The potential for a probiotic or bacteriocin to promote the regenerative potential of host reparative cells has not been previously documented. These findings have implications for the clinical sequelae of periodontal disease. Namely, in addition, to the aforementioned beneficial effects of nisin in mitigating periodontal disease bone loss and the host inflammatory response, while resetting the oral microbiome towards control levels, this additional finding suggests that nisin and a nisin probiotic may promote a regenerative potential and tissue restitution following disease.

Limited studies have examined a probiotic's ability to shift a disease-associated oral microbiome. In humans, one study found that lozenges containing $L$. rhamnosus GG and Bifidobacterium animalis mediated no change in the microbial composition of saliva using a focused oral microbe microarray[67]. One study in rats, using Bifidobacterium animalis subspecies lactis showed an increase in the levels of Actinomyces and Streptococci-like species while decreasing the levels of Veillonella parvula, Capnocytophaga sputigena, Eikenella corrodens, and Prevotella intermedia-like species[59]. Importantly, the current study revealed that the probioltic $L$. lactis and its bacteriocin nisin can shift a disease-associated oral bacteriome and virome back towards a healthier state (Fig. 5B and C). This agrees with our recent in vitro findings in oral biofilms that nisin and a nisin probiotic shift periodontal pathogen-spiked oral biofilms back towards a control/healthy state[42]. Maintaining or promoting a healthy microbiome in the course of treatment with probiotics is being recognized as an important parameter that should be evaluated[68,69, 70]. In this study, we used the approach of identifying the complex microbial signature of periodontal health as a baseline for comparison to evaluate and confirm a restitution of "health" following antimicrobial treatment for periodontal disease.

A long-standing premise in the pathogenesis of periodontal disease has been its association with pathogenic bacteria, especially members of the so called Red Complex. The current study and others highlight the importance of new and emerging microbes, both bacteria and viruses, in periodontal disease pathogenesis[12, 71-76] and their potential shift with treatment[72, 77]. These microbes may be important signatures useful in monitoring treatment and to determine shifts that signify health. We observed that the species Marinobacter sp. B9-2 was in higher abundance in the healthy control group compared to the infection group. However, 3 viruses, Golden Hamster Intracisternal A-particle H18, Bat gammaretrovirus, and Porcine type C oncovirus showed increased abundance $(F D R<0.2)$ in the infection group compared to the control group and also relative to other treatment groups (Fig. 6B). Thus, periodontal health was associated with Marinobacter sp. B9-2, whereas the 3 viruses, Golden Hamster Intracisternal A-particle H18, Bat gammaretrovirus, and Porcine type $C$ oncovirus, were associated with periodontal disease. These findings are consistent with our earlier observations showing that these three viral infectionassociated microbes were also associated with bone loss, whereas Marinobacter decreased with bone loss[12]. Treatment generally shifted microbes towards the healthy control. The significance of these specific microbes and their role in health and disease and response to treatment has not been previously described. Marinobacter is a genus of Proteobacteria found in sea water and a number of strains and species can degrade hydrocarbons[78]. Intracisternal type A particles are defective retroviruses in rodent genomes[79]. Bat gammaretrovirus are retroviruses that can cause malignancies and immune deficiencies in mammals, reptiles and birds[80]. Porcine type $\mathrm{C}$ oncovirus is a type of gammaretrovirus that lives in extreme environments and can be found in the human microbiome[81]. Further study is warranted to determine the relevance of these microbes in human oral health and disease.

Several of these microbial species were also significantly correlated with the cytokine host immune response. Namely, s_Golden hamster intracisternal $A$ particle H18 (highest correlation), s_Bat gammaretrovirus, s_Salmonella enterica, and s_Porcine type-C oncovirus exhibited a significant correlation with IL-6 levels. However, $s \_$Marinobacter sp.B9-2 was significantly negatively correlated with IL-6 levels. These findings further highlight the tight relationship between the microbiome and the host immune response; an interaction well known in conditions of health and disease[82].

\section{Conclusions}


In summary, this study highlights an approach to realign the oral microbial dysbiosis of periodontal disease and its related sequalae (bone loss, host immune response) towards health. Treatment with antibiotics and probiotics have been used to modulate the microbial, immunological, and clinical landscape of periodontal disease with some success. Antibacterial peptides or bacteriocins, such as nisin, and nisin-producing probiotics, such as Lactococcus lactis, have not been examined in this context. However, they warrant examination because of their well characterized biomedical benefits in eradicating biofilms and oral pathogenic bacteria, while also modulating immune mechanisms. This study demonstrates that nisin and nisin probiotic treatment inhibit periodontal disease-related bone loss and host immune responses while significantly shifting the oral bacteriome and virome towards the healthy control state. This shift was characterized by a unique signature where health was associated with a Proteobacteria (Marinobacter sp. B9-2), whereas 3 retroviruses (Golden Hamster Intracisternal A-particle H18, Bat gammaretrovirus, and Porcine type C oncovirus) were associated with disease. The ability to shift the oral microbiome towards health may be a useful approach to treating periodontal disease in vivo. Further, the novel discovery that nisin and a nisin probiotic promote the numbers of host reparative cells reveals a potentially new biomedical application for nisin in regenerative medicine. Nisin's ability to shift the oral microbiome towards health, mitigate oral disease, and promote a regenerative periodontal phenotype may benefit the regenerative potential of the periodontium and negate systemic effects associated with periodontal disease and its pathogens.

\section{Declarations}

\section{ETHICS APPROVAL STATEMENT}

The use of animals for these studies was approved by the Institutional Animal Care and Use Committee of the University of California, San Francisco (IACUC APPROVAL NUMBER: AN171564-01B).

\section{CONSENT FOR PUBLICATION}

Not applicable

\section{DATA AVAILABILITY}

The data and code are available at

https://figshare.com/articles/dataset/Nisin_Probiotic_Prevents_Periodontal_Disease_and_Inflammation_while_Promoting_Periodontal_Regeneration_and_Shif

\section{COMPETING INTERESTS}

MRS, MJZ, and YLK are members of Oralome

\section{FUNDING}

This study was supported by an NIH R01 DE025225 grant and AAP Sunstar Innovation grant to Y.L.K. L.G. was supported by a grant from the Chinese Scholarship Council.

\section{AUTHOR CONTRIBUTIONS}

L.G., R.K., M.J.Z., A.M., P.K., C.L., L.Z., C.Y., H.R., M.R.S, and Y.L.K. all contributed to all four of the following aspects of authorship: (1) substantial contributions to the conception or design of the work or the acquisition, analysis or interpretation of the data, (2) drafting the work or revising it critically for important intellectual content, (3) final approval of the completed version, (4) accountability for all aspects of the work in ensuring that questions related to the accuracy or integrity of any part of the work are appropriately investigated and resolved.

\section{ACKNOWLEDGEMENTS}

We acknowledge the support of the many facilities at UCSF that made this study possible.

\section{References}

1. Epidemiology. etiology, and prevention of periodontal diseases. Report of a.

2. WHO Scientific Group. World Health Organ Tech Rep Ser. 1978;621:1-60.

3. Tatakis DN, Kumar PS. Etiology and pathogenesis of periodontal diseases. Dent Clin North Am. 2005;49:491-516.

4. Kim J, Amar S. Periodontal disease and systemic conditions: a bidirectional relationship. Odontology. 2006;94:10-21.

5. Kapila Y. Oral health's inextricable connection to systemic health - special populations bring to bear multimodal relationships and factors connecting periodontal disease to systemic diseases and conditions. Periodontol 2000. (In press) (2021).

6. Linden GJ, Lyons A, Scannapieco FA. Periodontal systemic associations: review of the evidence. J Periodontol. 2013;84 suppl:8-19.

7. Dominy SS, Lynch C, Ermini F, Benedyk M, Marczyk A, Konradi A, et al. Porphyromonas gingivalis in Alzheimer's disease brains: Evidence for disease causation and treatment with small-molecule inhibitors. Sci Adv. 2019;5:eaau3333.

8. Hajishengallis G, Darveau RP, Curtis MA. The keystone pathogen hypothesis. Nat Rev Microbiol. 2012;10:717-25. 
9. Nibali L. Aggressive periodontitis: microbes and host response, who to blame? Virulence. 2015; 6: 223-28.

10. Kuang X, Chen V, Xu X. Novel approaches to the control of oral microbial.

11. Biofilms. Biomed Res. 2018;31:6498932.

12. Paster BJ, Boches SK, Galvin JL, Ericson RE, Lau CN, Levanos VA, et al. Bacterial diversity in human subgingival plaque. J Bacteriol. 2001;183:3770-83.

13. Socransky SS, Haffajee AD, Cugini MA, Smith C. Kent RL Jr.

14. Microbial complexes. in subgingival plaque. J Clin Periodontol. 1998;25:134e144.

15. Gao L, Kang M, Zhang MJ, Reza Sailani M, Kuraji R, Martinez A, et al. Polymicrobial periodontal disease triggers a wide radius of effect and unique virome. NPJ Biofilms Microbiomes. 2020;6:10.

16. Rickard AH, Gilbert P, High NJ, Kolenbrander PE, Handley PS. Bacterial coaggregation: An integral process in the development of multi-species biofilms. Trends In Microbiology. 2003;11:94-100.

17. Rivera MF, Lee JY, Aneja M, Goswami V, Liu L, Velsko IM, et al. Polymicrobial infection with major periodontal pathogens induced periodontal disease and aortic atherosclerosis in hyperlipidemic ApoE(null) mice. PLoS One. 2013;8:e57178.

18. Shrestha D, Choi YH, Zhang J, Hazlett LJ, Merchant AT. Relationship between serologic markers of periodontal bacteria and metabolic syndrome and its components. J Periodontol. 2015;86:418-30.

19. Chukkapalli SS, Rivera MF, Velsko IM, Lee JY, Chen H, Zheng D, et al. Invasion of oral and aortic tissues by oral spirochete Treponema denticola in ApoE(-/-) mice causally links periodontal disease and atherosclerosis. Infect Immun. 2014;82:1959-67.

20. Kudo Y, Tada H, Fujiwara N, Tada Y, Tsunematsu T, Miyake Y,et al. Oral environment and cancer. Genes Environ. 2016;38:13.

21. Teughels W, Durukan A, Ozcelik O, Pauwels M, Quirynen M, Haytac MC. Clinical and microbiological effects of lactobacillus reuteri probiotics in the treatment of chronic periodontitis: a randomized placebo-controlled study. J Clin Periodontol. 2013;40:1025-35.

22. Becker DE. Drug allergies and implications for dental practice. AnesthProg. 2013;60:188-97.

23. Becker DE. Antimicrobial drugs. AnesthProg. 2013;60:111-22.

24. Meurman JH, Stamatova I. Probiotics: contributions to oral health. Oral Dis. $2007 ; 13,443-51$.

25. Laleman I, Teughels W. Probiotics in the dental practice: a review. Quintessence Int. 2015, 46, 255 - 64.

26. Hill C, Guarner F, Reid G, Gibson GR, Merenstein DJ, Pot B, et al. Expert consensus document. The International Scientific Association for Probiotics and Prebiotics consensus statement on the scope and appropriate use of the term probiotic. Nat Rev.

27. Gastroenterol H. 2014; 11: 506-14.

28. Nguyen T, Brody H, Lin GH, Rangé H, Kuraji R, Ye C, et al. Probiotics, including nisin-based probiotics, improve clinical and microbial outcomes relevant to oral and systemic diseases. Periodontol 2000. 2020; 82: $173-85$.

29. Tekce M, Ince G, Gursoy H, Dirikan Ipci S, Cakar G, Kadir T, et al. Clinical and microbiological effects of probiotic lozenges in the treatment of chronic periodontitis: a 1-year follow-up study. J Clin Periodontol. 2015;42:363-72.

30. İnce G, Gürsoy H, İpçi ŞD, Cakar G, Emekli-Alturfan E, Yılmaz S. Clinical and biochemical evaluation of Lactobacillus reuteri containing lozenges as an adjunct to non-surgical periodontal therapy in chronic periodontitis. J Periodontol. 2015;86:746-54.

31. Kobayashi R, Kobayashi T, Sakai F, Hosoya T, Yamamoto M, Kurita-Ochiai T. Oral administration of Lactobacillus gasseri SBT2055 is effective in preventing Porphyromonas gingivalis-accelerated periodontal disease. Sci Rep. 2017;7:545.

32. Albuquerque-Souza E, Balzarini D, Ando-Suguimoto ES. Ishikawa KH, Simionato.

33. Holzhausen MRL. M, et al. Probiotics alter the immune response of gingival epithelial cells challenged by Porphyromonas gingivalis. J Periodontal Res. 2019;54:115-27.

34. Liu TH, Tsai TY, Pan TM. Effects of an ethanol extract from Lactobacillus paracasei subsp. paracasei NTU101 fermented skimmed milk on lipopolysaccharide-induced periodontal inflammation in rats. Food Funct. 2018;9:4916-25.

35. Ikram S, Hassan N, Baig S, Borges KJJ, Raffat MA, Akram Z. Effect of local probiotic (Lactobacillus reuteri) vs systemic antibiotic therapy as an adjunct to non-surgical periodontal treatment in chronic periodontitis. J Investig Clin Dent. 2019;10:e12393.

36. Invernici MM, Salvador SL, Silva PHF, Soares MSM, Casarin R, Palioto DB, et al. Effects of Bifidobacterium probiotic on the treatment of chronic periodontitis: A randomized clinical trial. J Clin Periodontol. 2018;45:1198-210.

37. Laleman I, Yilmaz E, Ozcelik O, Haytac C, Pauwels M, Herrero ER,et al. The effect of a streptococci containing probiotic in periodontal therapy: a randomized controlled trial. J Clin Periodontol. 2015;42:1032-41.

38. Montero E, Iniesta M, Rodrigo M, Marín MJ, Figuero E, Herrera D, et al. Clinical and microbiological effects of the adjunctive use of probiotics in the treatment of gingivitis: A randomized controlled clinical trial. J Clin Periodontol. 2017;44:708-16.

39. Jaffar N, Ishikawa Y, Mizuno K, Okinaga T, Maeda T. Mature Biofilm Degradation by Potential Probiotics: Aggregatibacter actinomycetemcomitans versus Lactobacillus spp. PLoS One. 2016;11:e0159466.

40. Schmitter T, Fiebich BL, Fischer JT, Gajfulin M, Larsson N, Rose T, et al. Ex vivo anti-inflammatory effects of probiotics for periodontal health. J Oral Microbiol. 2018;10:1502027.

41. Hurst A. Nisin. Adv Appl Microbiol. 1981;27:85-123.

42. Shin JM, Gwak JW, Kamarajan P, Fenno JC, Rickard AH. Kapila YL. Biomedical.

43. applications of nisin. J Appl Microbiol. 2016;120:1449-65.

Page $10 / 18$ 
44. Howell TH, Fiorellini JP, Blackburn P, Projan SJ, de la Harpe J, Williams RC. The effect of a mouthrinse based on nisin, a bacteriocin, on developing plaque and gingivitis in beagle dogs. J Clin Periodontol. 1993;20:335-39.

45. Cunha E, Trovão T, Pinheiro A, Nunes T, Santos R, Moreira da Silva J, et al. Potential of two delivery systems for nisin topical application to dental plaque biofilms in dogs. BMC Vet Res. 2018;14:375.

46. Shin JM, Ateia I, Paulus JR, Liu H, Fenno JC, Rickard AH, et al. Antimicrobial nisin acts against saliva derived multi-species biofilms without cytotoxicity to human oral cells. Front Microbiol. 2015;6:617.

47. Kajwadkar R, Shin JM, Lin GH, Fenno JC, Rickard AH, Kapila YL. High-purity nisin alone or in combination with sodium hypochlorite is effective against planktonic and biofilm populations of Enterococcus faecalis. J Endod. 2017;43:989-94.

48. Radaic A, Ye C, Parks B, Gao L, Kuraji R, Malone E, et al. Modulation of pathogenic oral biofilms towards health with nisin probiotic. J Oral Microbiol. 2020;12:1809302.

49. Gough R, Cabrera Rubio R, O'Connor PM, Crispie F, Brodkorb A, Miao S, et al. Oral delivery of nisin in resistant starch based matrices alters the gut microbiota in mice. Front Microbiol. 2018;9:1186.

50. Mayanagi G, Kimura M, Nakaya S, Hirata H, Sakamoto M, Benno Y, et al. Probiotic effects of orally administered Lactobacillus salivarius WB21-containing tablets on periodontopathic bacteria: a double-blinded, placebo-controlled, randomized clinical trial. J Clin Periodontol. 2009;36:506-13.

51. Iniesta M, Herrera D, Montero E, Zurbriggen M, Matos AR, Marín MJ, et al. Probiotic effects of orally administered Lactobacillus reuteri-containing tablets on the subgingival and salivary microbiota in patients with gingivitis. A randomized clinical trial. J Clin.

52. Periodontol. 2012; 39: $736-44$.

53. Vivekananda MR, Vandana KL, Bhat KG. Effect of the probiotic Lactobacilli reuteri (Prodentis) in the management of periodontal disease: a preliminary randomized clinical trial. J Oral Microbiol. 2010;2:2.

54. Tekce M, Ince G, Gursoy H, Dirikan Ipci S, Cakar G, Kadir T, et al. Clinical and microbiological effects of probiotic lozenges in the treatment of chronic periodontitis: a 1-year follow-up study. J Clin Periodontol. 2015;42:363-72.

55. Tsubura S, Mizunuma H, Ishikawa S, Oyake I, Okabayashi M, Katoh K, et al. The effect of Bacillus subtilis mouth rinsing in patients with periodontitis. Eur J Clin Microbiol Infect Dis. 2009;28:1353-56.

56. Morales A, Gandolfo A, Bravo J, Carvajal P, Silva N, Godoy C, et al. Microbiological and clinical effects of probiotics and antibiotics on nonsurgical treatment of chronic periodontitis: a randomized placebo- controlled trial with 9-month follow-up. J Appl Oral Sci. 2018;26:e20170075.

57. Zahradnik RT, Magnusson I, Walker C, McDonell E, Hillman CH, Hillman JD. Preliminary assessment of safety and effectiveness in humans of ProBiora3, a probiotic mouthwash. J Appl Microbiol. 2009;107:682-90.

58. Maekawa T, Hajishengallis G. Topical treatment with probiotic Lactobacillus brevis CD2 inhibits experimental periodontal inflammation and bone loss. J Periodontal Res. 2014;49:785-91.

59. Ricoldi MST, Furlaneto FAC, Oliveira LFF, Teixeira GC, Pischiotini JP, Moreira ALG, et al. Effects of the probiotic Bifidobacterium animalis subsp. lactis on the non-surgical treatment of periodontitis. A histomorphometric, microtomographic and immunohistochemical study in rats. PLoS One. 2017;12:e0179946.

60. Gatej SM, Marino V, Bright R, Fitzsimmons TR, Gully N, Zilm P, et al. Probiotic Lactobacillus rhamnosus GG prevents alveolar bone loss in a mouse model of experimental periodontitis. J Clin Periodontol. 2018;45:204-12.

61. Nackaerts O, Jacobs R, Quirynen M, Rober M, Sun Y, Teughels W. Replacement therapy for periodontitis: pilot radiographic evaluation in a dog model. J Clin Periodontol. 2008;35:1048-52.

62. Messora MR, Oliveira LF, Foureaux RC, Taba M Jr, Zangerônimo MG, Furlaneto FA,et al. Probiotic therapy reduces periodontal tissue destruction and improves the intestinal morphology in rats with ligature-induced periodontitis. J Periodontol. 2013;84:1818-26.

63. Foureaux Rde C, Messora MR, de Oliveira LF, Napimoga MH. Pereira AN, Ferreira.

64. MS. et al. Effects of probiotic therapy on metabolic and inflammatory parameters of rats with ligature-induced periodontitis associated with restraint stress. J Periodontol. 2014;85:975-83.

65. Garcia VG, Knoll LR, Longo M, Novaes VC, Assem NZ, Ervolino E, et al. Effect of the probiotic Saccharomyces cerevisiae on ligature-induced periodontitis in rats. J Periodontal Res. 2016;51:26-37.

66. Messora MR, Pereira LJ, Foureaux R, Oliveira LF, Sordi CG, Alves AJ, et al. Favourable effects of Bacillus subtilis and Bacillus licheniformis on experimental periodontitis in rats. Arch Oral Biol. 2016;66:108-19.

67. Oliveira LF, Salvador SL, Silva PH, Furlaneto FA, Figueiredo L, Casarin R, et al. Benefits of Bifidobacterium animalis subsp. lactis probiotic in experimental periodontitis. J Periodontol. 2017;88:197-208.

68. Rana S, Bhawal S, Kumari A, Kapila S, Kapila R. pH-dependent inhibition of AHL-mediated quorum sensing by cell-free supernatant of lactic acid bacteria in Pseudomonas aeruginosa PA01. Microb Pathog. 2020;142:104105.

69. Staab B, Eick S, Knöfler G, Jentsch H. The influence of a probiotic milk drink on the development of gingivitis: a pilot study. J Clin Periodontol. 2009;36:850-56.

70. Twetman S, Derawi B, Keller M, Ekstrand K, Yucel-Lindberg T, Stecksen-Blicks C. Short-term effect of chewing gums containing probiotic Lactobacillus reuteri on the levels of inflammatory mediators in gingival crevicular fluid. Acta Odontol Scand. 2009;67:19-24.

71. Lee JK, Kim SJ, Ko SH, Ouwehand AC, Ma DS. Modulation of the host response by probiotic Lactobacillus brevis CD2 in experimental gingivitis. Oral Dis. 2015;21:705-12. 
72. Kuru BE, Laleman I, Yalnızoğlu T, Kuru L, Teughels W. The Influence of a Bifıdobacterium animalis Probiotic on Gingival Health: A Randomized Controlled Clinical Trial. J Periodontol. 2017;88:1115-23.

73. Szkaradkiewicz AK, Stopa J, Karpiński TM. Effect of oral administration involving a probiotic strain of Lactobacillus reuteri on pro-inflammatory cytokine response in patients with chronic periodontitis. Arch Immunol Ther Exp (Warsz). 2014;62:495-500.

74. Khasenbekova Z, Saduakhasova S, Gulayev A, Kushugulova A, Kozhakhmetov S.

75. Shakhabayeva G, et al. Effect of probiotic consortium on the local inflammatory process in chronic periodontitis. Cent Asian J Glob Health. 2014;2 Suppl:109.

76. Toiviainen A, Jalasvuori H, Lahti E, Gursoy U, Salminen S, Fontana M, et al. Impact of orally administered lozenges with Lactobacillus rhamnosus GG and Bifidobacterium animalis subsp. lactis BB-12 on the number of salivary mutans streptococci, amount of plaque, gingival inflammation and the oral microbiome in healthy adults. Clin Oral Investig. 2015;19:77-83.

77. Ghyselinck J, Verstrepen L, Moens F, Van den Abbeele P, Said J, Smith B, et al. A 4-strain probiotic supplement influences gut microbiota composition and gut wall function in patients with ulcerative colitis. Int J Pharm. 2020;587:119648.

78. Tankou SK, Regev K, Healy BC, Tjon E, Laghi L, Cox LM, et al. A probiotic modulates the microbiome and immunity in multiple sclerosis. Ann Neurol. 2018;83:1147-61.

79. Kristensen M, Prevaes SMPJ, Kalkman G, Tramper-Stranders GA, Hasrat R de.

80. Winter-de Groot KM, et al. Development of the gut microbiota in early life: The impact of cystic fibrosis and antibiotic treatment. J Cyst Fibros. 2020;19:553-61.

81. Kushkevych I, Coufalová M, Vítězová M, Rittmann SKR. Sulfate-reducing bacteria of the oral cavity and their relation with periodontitis-recent advances. J Clin Med. 2020; 9, pii: E2347.

82. Ko Y, Lee EM, Park JC, Gu MB, Bak S, Ji S. Salivary microbiota in periodontal health and disease and their changes following nonsurgical periodontal treatment. J Periodontal Implant Sci. 2020;50:171-82.

83. Zhang Y, Li F, Chen X, Shan TL, Deng XT, Delwart E, et al. Detection of a new species of torque teno mini virus from the gingival epithelium of patients with periodontitis. Virus Genes. 2017;53:823-30.

84. Abbas AA, Taylor LJ, Dothard MI, Leiby JS, Fitzgerald AS, Khatib LA, et al. Redondoviridae, a family of small, circular DNA viruses of the human ororespiratory tract associated with periodontitis and critical illness. Cell Host Microbe. 2019;26:297.

85. Zhang Y, Shan TL, Li F, Yu T, Chen X, Deng XT, et al. A novel phage from periodontal pockets associated with chronic periodontitis. Virus Genes. 2019;55:381-93.

86. Santiago-Rodriguez TM, Naidu M, Abeles SR, Boehm TK, Ly M, Pride DT. Transcriptome analysis of bacteriophage communities in periodontal health and disease. BMC Genom. 2015;16:549.

87. Lu H, Zhao Y, Feng X, He L, Meng H. Microbiome in maintained periodontitis and its shift over a single maintenance interval of 3 months. J Clin Periodontol. 2019;46:1094-104.

88. Brito EM, Guyoneaud R, Goñi-Urriza M, Ranchou-Peyruse A, Verbaere A. Crapez.

89. MA. et al. Characterization of hydrocarbonoclastic bacterial communities from mangrove sediments in Guanabara Bay. Brazil Res Microbiol. 2006;157:752-62.

90. Kuff EL, Lueders KK. The intracisternal A-particle gene family: structure and functional aspects. Adv Cancer Res. 1988;51:183-276.

91. Murphy FA. Gibbs EPJ, Horzinek MC. Studdert MJ. Veterinary virology. (3rd ed.) San Diego, Academic Press; 1999.

92. Todaro GJ. Type C. virogenes: modes of transmission and evolutionary aspects. Hamatol Bluttransfus. 1976;19:357-74.

93. Zheng D, Liwinski T, Elinav E. Interaction between microbiota and immunity in.

94. health and disease. Cell Res. 2020;30:492-506.

95. Kesavalu L, Sathishkumar S, Bakthavatchalu V, Matthews C, Dawson D, Steffen M, et al. Rat model of polymicrobial infection, immunity, and alveolar bone resorption in periodontal disease. Infect Immun. 2007;75:1704-712.

96. Xie H, Hong J, Sharma A, Wang BY. Streptococcus cristatus ArcA interferes with Porphyromonas gingivalis pathogenicity in mice. J Periodontal Res. 2012;47:578-83.

97. Sharma A, Inagaki S, Honma K, Sfintescu C, Baker PJ, Evans RT. Tannerella forsythia-induced alveolar bone loss in mice involves leucine-rich-repeat BspA Protein. J Dent Res. 2005;84:462-67.

98. Kuraji R, Wu YH, Hashimoto S, Mishiro S, Maeda Y, Miyashita Y, et al. Temporal and dynamic changes in gingival blood flow during progression of ligature-induced periodontitis. Oral Dis. 2020. doi:10.1111/odi.13328.

99. Yoav B, Yosef Hochberg. "Controlling the false discovery rate: a practical and powerful approach to multiple testing.". J R Stat Soc. 1995;57(1):289-300.

\section{Figures}


A.

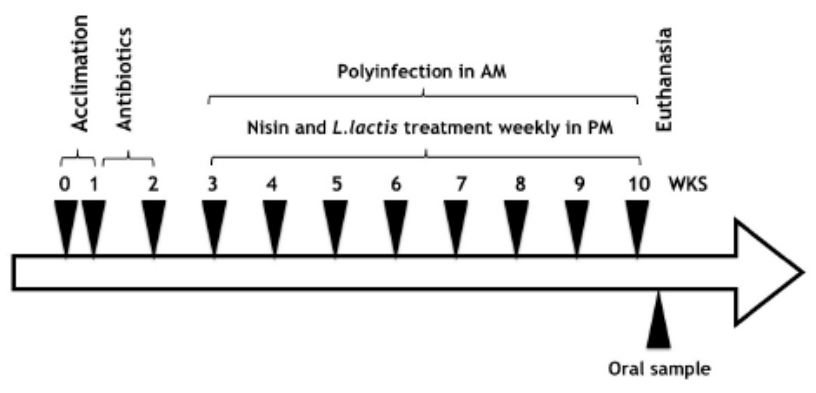

B.

\begin{tabular}{|c|c|c|c|c|}
\hline \multicolumn{5}{|c|}{ Experimental Groups - Infection and Treatment Protocol } \\
\hline Group & Name/Label & Treatment & $\begin{array}{c}\text { Treatment in the morning } \\
(4 \text { days per week) }\end{array}$ & $\begin{array}{c}\text { Treatment in the evening } \\
\text { (daily) }\end{array}$ \\
\hline $\mathbf{1}$ & Control & Control & $2 \% \mathrm{CMC}$ & $2 \% \mathrm{CMC}$ \\
\hline $\mathbf{2}$ & Infection (Inf) & Infection & Polyinfection & $2 \% \mathrm{CMC}$ \\
\hline $\mathbf{3}$ & Nisin low (L) & Nisin $(100 \mu \mathrm{g} / \mathrm{ml})$ & $2 \% \mathrm{CMC}$ & nisin $(100 \mu \mathrm{g} / \mathrm{ml})$ \\
\hline $\mathbf{4}$ & Nisin high $(\mathrm{H})$ & Nisin $(300 \mu \mathrm{g} / \mathrm{ml})$ & $2 \% \mathrm{CMC}$ & nisin $(300 \mu \mathrm{g} / \mathrm{ml})$ \\
\hline $\mathbf{5}$ & L. lactis & Nisin-producing L. lactis & $2 \% \mathrm{CMC}$ & nisin producing L. lactis \\
\hline $\mathbf{6}$ & Non-nisin L. lactis & Non-nisin producing L. lactis & $2 \% \mathrm{CMC}$ & non-nisin producing L. lactis \\
\hline $\mathbf{7}$ & Inf + nisin (L) & Infection + nisin $(100 \mu \mathrm{g} / \mathrm{ml})$ & polyinfection & nisin $(100 \mu \mathrm{g} / \mathrm{ml})$ \\
\hline $\mathbf{8}$ & Inf + nisin $(\mathrm{H})$ & Infection + nisin $(300 \mu \mathrm{g} / \mathrm{ml})$ & polyinfection & nisin $(300 \mu \mathrm{g} / \mathrm{ml})$ \\
\hline $\mathbf{9}$ & Inf + L. lactis & infection + nisin producing L. lactis & polyinfection & nisin producing L. lactis \\
\hline $\mathbf{1 0}$ & Inf + non-nisin L. lactis & infection + non-nisin producing L. lactis & polyinfection & non-nisin producing L. lactis \\
\hline
\end{tabular}

Figure 1

Mouse treatment procedure and oral sample collection timeline. Polymicrobial infections were carried out in the morning for 4 consecutive days once per week from the 3rd to the 10th week. Nisin and L. lactis were administered every day in the evening from the 3rd to the 10th week. Oral swab samples were collected at 8 weeks following the initial infection. Blood and tissue specimen collection was performed at euthanasia following 8 weeks of infection.

A.

B.

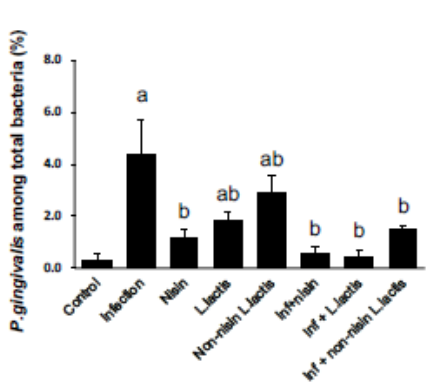

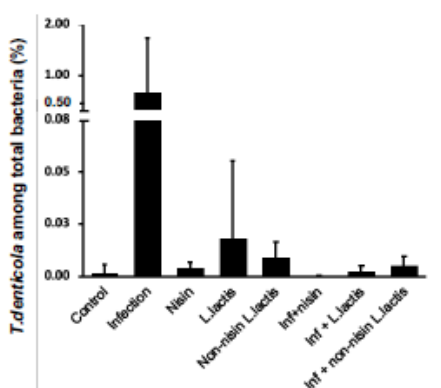

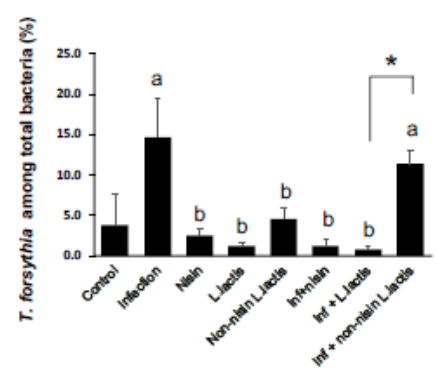

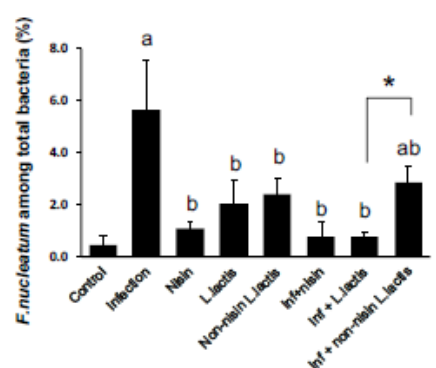

Presences of Periodontal Pathogens / Number of Mice (\%)

\begin{tabular}{|c|c|c|c|c|c|c|c|c|}
\hline & Control & Infection & Nisin & L. lactis & Non-nisin L. lactis & Inf + nisin & Inf $+L$. lactis & $\begin{array}{c}\text { Inf + Non-nisin } L . \\
\text { lactis }\end{array}$ \\
\hline P. gingivalis & $\begin{array}{c}11.42 \pm 3.89 \\
(100 \%)\end{array}$ & $\begin{array}{c}397.90 \pm 276.76 \\
(100 \%)\end{array}$ & $\begin{array}{c}33.95 \pm 27.18 \\
(100 \%)\end{array}$ & $\begin{array}{c}12.00 \pm 6.81 \\
(100 \%)\end{array}$ & $\begin{array}{c}1.18 \pm 2.05 \\
(100 \%)\end{array}$ & $\begin{array}{c}6.70 \pm 4.08 \\
(100 \%)\end{array}$ & $\begin{array}{c}8.23 \pm 5.06 \\
(100 \%)\end{array}$ & $\begin{array}{c}21.73 \pm 1.87 \\
(100 \%)\end{array}$ \\
\hline T. denticola & $\begin{array}{c}0.04 \pm 42.48 \\
(33 \%)\end{array}$ & $\begin{array}{c}42.48 \pm 60.24 \\
(33 \%)\end{array}$ & $\begin{array}{c}0.11 \pm 0.03 \\
(67 \%)\end{array}$ & $\begin{array}{c}0.02 \pm 0.03 \\
(17 \%)\end{array}$ & $\begin{array}{c}0.02 \pm 0.02 \\
(33 \%)\end{array}$ & $\begin{array}{c}0.00 \pm 0.00 \\
(17 \%)\end{array}$ & $\begin{array}{c}0.02 \pm 0.03 \\
(33 \%)\end{array}$ & $\begin{array}{c}0.07 \pm 0.09 \\
(50 \%)\end{array}$ \\
\hline T. forsythia & $\begin{array}{c}381.87 \pm 329.50 \\
(100 \%)\end{array}$ & $\begin{array}{c}2,258.47 \pm 1,560.58 \\
(100 \%)\end{array}$ & $\begin{array}{c}74.14 \pm 48.07 \\
(100 \%)\end{array}$ & $\begin{array}{c}11.36 \pm 8.50 \\
(100 \%)\end{array}$ & $\begin{array}{c}13.05 \pm 9.34 \\
(100 \%)\end{array}$ & $\begin{array}{c}14.43 \pm 10.43 \\
(100 \%)\end{array}$ & $\begin{array}{c}13.53 \pm 8.24 \\
(100 \%)\end{array}$ & $\begin{array}{c}186.28 \pm 58.73 \\
(100 \%)\end{array}$ \\
\hline F. nucleatum & $\begin{array}{c}19.20 \pm 10.59 \\
(100 \%)\end{array}$ & $\begin{array}{c}479.84 \pm 260.55 \\
(100 \%)\end{array}$ & $\begin{array}{c}28.34 \pm 17.24 \\
(100 \%)\end{array}$ & $\begin{array}{c}12.61 \pm 3.50 \\
(100 \%)\end{array}$ & $\begin{array}{c}10.00 \pm 10.97 \\
(100 \%)\end{array}$ & $\begin{array}{c}16.22 \pm 17.55 \\
(100 \%)\end{array}$ & $\begin{array}{c}37.76 \pm 62.97 \\
(100 \%)\end{array}$ & $\begin{array}{c}45.23 \pm 22.49 \\
(100 \%)\end{array}$ \\
\hline
\end{tabular}

Actual numbers of bacteria / swab [mean $\pm \mathrm{SD}$ ]

(Presence of periodontal pathogens / number of mice [\%])

Figure 2

Polymicrobial oral infection is reduced by nisin or nisin-producing probiotic treatment. Oral swab samples were collected at eight weeks after polymicrobial infection. DNA was isolated and purified from the swab samples of eight groups (Control, Infection, Nisin (H), L. lactis, Non-nisin L. lactis, Infection + nisin (H), Infection + L. lactis and Infection + Non-nisin L. lactis). The total bacteria were quantified by standard real-time PCR using primers corresponding to $16 \mathrm{~S}$ ribosomal RNA. A. The data are shown as a percentage of each pathogen (P. gingivalis, T. denticola, T. forsythia, or F. nucleatum) among total bacteria. a, the difference in percentage of the pathogen was significant $(p<0.001)$ compared to the Control group. $b$, the difference in percentage of the pathogen was 
significant $(p<0.01)$ compared to the Infection group. *, the difference in percentage of the pathogen between the two groups was significant $(p<0.05)$. B. The table demonstrates the number of detected bacteria and detection frequency (\%) of periodontal pathogens in each swab from each mouse relative to the number of collected samples.

A.
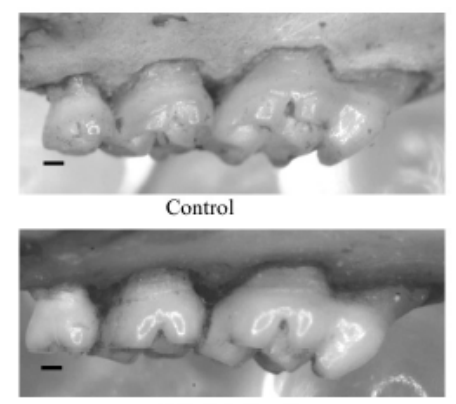

Inf + nisin(Low)

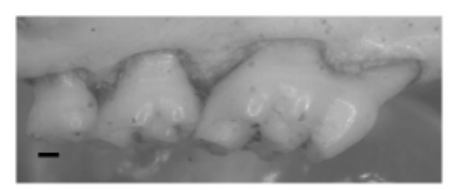

Inf + L.lactis

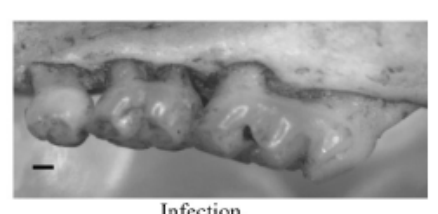

Infection

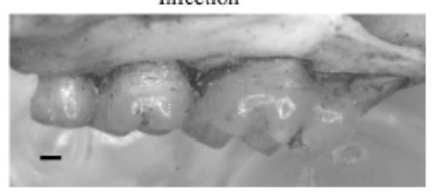

Inf + nisin(High)

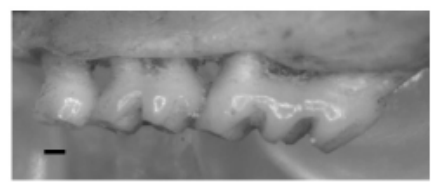

Inf + non-nisin L.lactis
B.

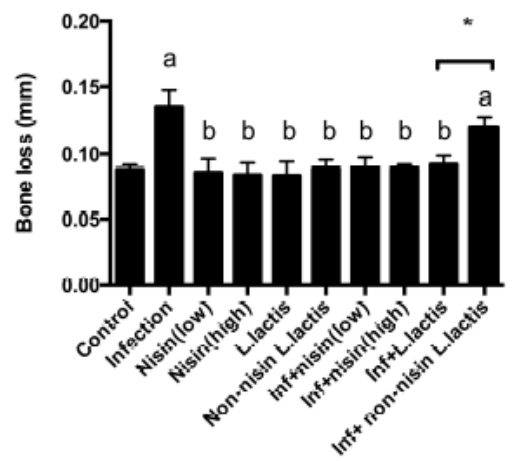

c.

\begin{tabular}{|l|l|} 
Group & Intrabony Defects (\%) \\
\hline Control & $14 / 72(19)$ \\
\hline Infection & $42 / 72(58)^{\mathrm{a}}$ \\
\hline Nisin $(100 \mu \mathrm{g} / \mathrm{ml})$ & $15 / 72(21)^{\mathrm{b}}$ \\
\hline Nisin $(300 \mu \mathrm{g} / \mathrm{ml})$ & $14 / 72(19)^{\mathrm{b}}$ \\
\hline L. lactis & $14 / 72(19)^{\mathrm{b}}$ \\
\hline Non-nisin L. lactis & $15 / 72(21)^{\mathrm{b}}$ \\
\hline Infection + nisin $(100 \mu \mathrm{g} / \mathrm{ml})$ & $22 / 72(31)^{\mathrm{b}}$ \\
\hline Infection + nisin $(300 \mu \mathrm{g} / \mathrm{ml})$ & $16 / 72(22)^{\mathrm{b}}$ \\
\hline Infection + L. Iactis & $24 / 72(33)^{\mathrm{bc}}$ \\
\hline Infection + non-nisin L. lactis & $35 / 72(49)^{\mathrm{sc}}$ \\
\hline
\end{tabular}

Figure 3

Alveolar bone loss is significantly abrogated with nisin or nisin-producing probiotic treatment. A. Representative images of alveolar bone loss on the palatal surfaces of maxillary molars in six groups (Control, Infection, Infection + nisin (L), Infection + nisin (H), Infection + L. lactis and Infection + Non-nisin L. Iactis). Scale bar represents $0.2 \mathrm{~mm}$. B. The graph represents alveolar bone loss in all ten groups. Data represent the means \pm standard deviation from 6 mice per group. For each mouse, alveolar bone loss was calculated as the average from 28 sites ( 3 sites on the first molar, 2 sites on the second molar, and 2 sites on the third molar, on both sides of the left maxilla and mandible). a, the difference in alveolar bone loss was significant $(p<0.05)$ compared to the Control group. $b$, the difference in alveolar bone loss was significant $(p<0.05)$ compared to the Infection group. * , the difference in alveolar bone loss between the two groups was significant $(p<0.05)$. C. The percentage of intrabony defects was calculated as the number of tooth surfaces containing periodontal intrabony defects out of total tooth surfaces. For each group, there were a total of 72 tooth surfaces ( 6 mice, 36 molars, 72 sides (buccal, palatal/lingual)). a, the difference in the percentage of intrabony defect was significant $(p<0.05)$ compared to the Control group. b, the difference in the percentage of intrabony defect was significant $(p<0.05)$ compared to the Infection group. $c$, there was no significant difference in the percentage of intrabony defect between the Infection + L. lactis group and Infection + non-nisin L. lactis group $(p>0.05)$. 


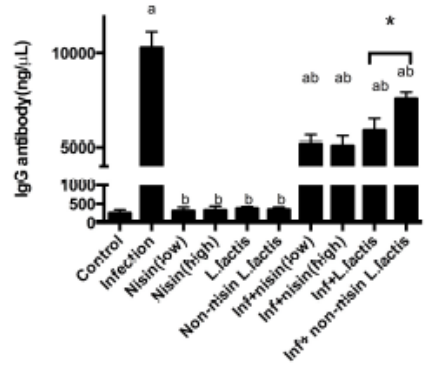

Anti-P. gingivalis

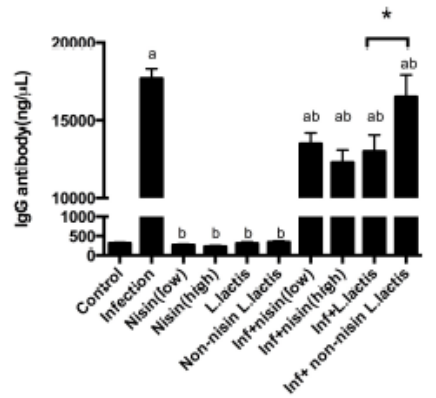

Anti-F. nucleatum

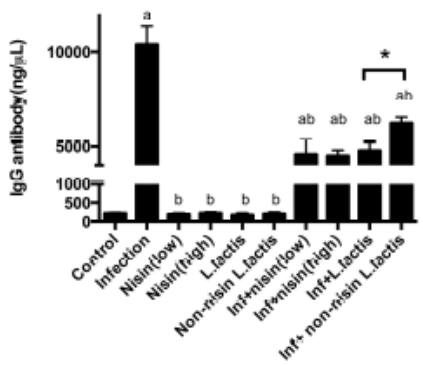

Anti-T. denticola

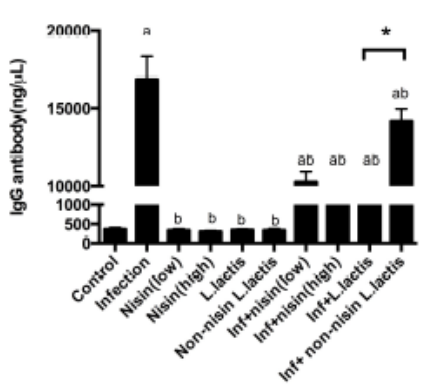

Anti-T. forthysia

Figure 4

Host antibody response against periodontal pathogens is significantly abrogated with nisin or nisin-producing probiotic treatment. Serum IgG antibody levels to P. gingivalis, T. denticola, T. forsythia , and F. nucleatum in all ten groups. Data represent the means \pm standard deviation from 6 mice per group. a, the difference in serum IgG antibody levels was significant $(p<0.05)$ compared to the Control group. $b$, the difference in serum IgG antibody levels was significant $(p<0.05)$ compared to the Infection group. ${ }^{*}$, the difference in serum IgG antibody levels between the two groups was significant $(p<0.05)$.

A.

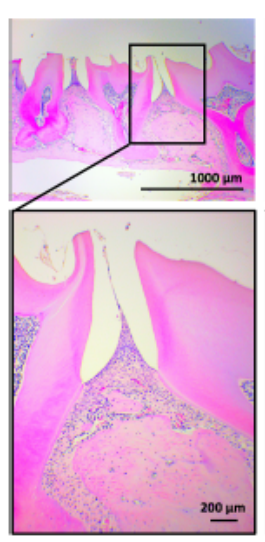

B.

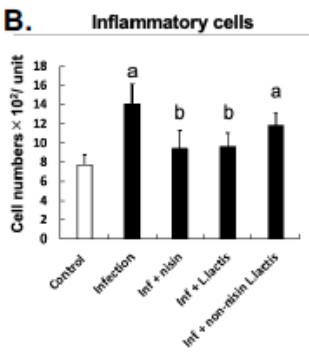

Infection

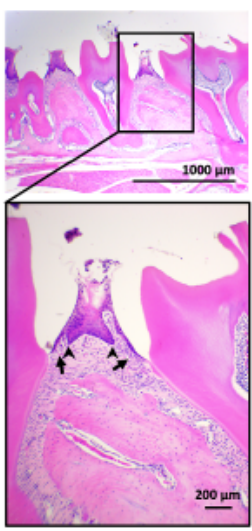

Inf + nisin

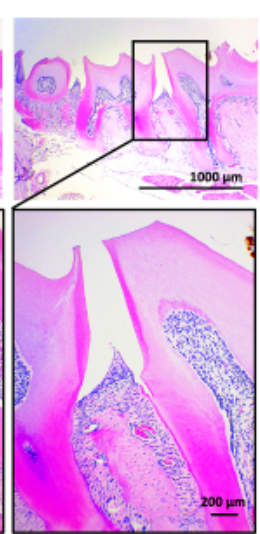

Inf + L.lactis

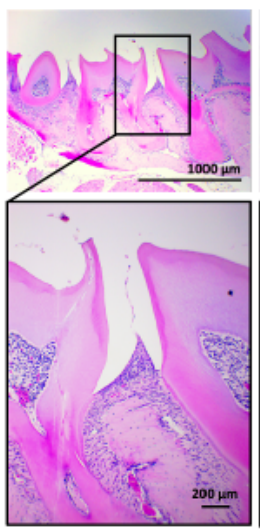

Inf + non-nisin L.lactis

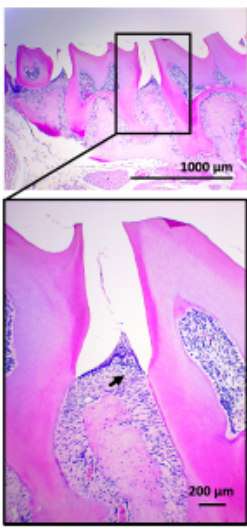

Alveolar bone

lining cells

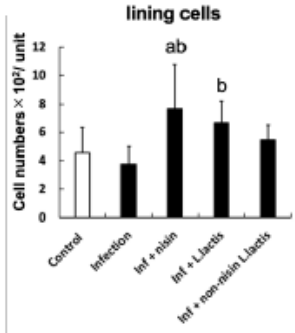

Figure 5

Nisin or nisin-producing probiotic prevent an influx of inflammatory cells into the periodontal complex, and promote increases in host regenerative periodontal cells. Histological examination of periodontal inflammation in the interproximal area between the first and second maxillary molars was performed in 5 groups (Control, Infection, Infection + nisin (H), Infection + L. lactis and Infection + Non-nisin L. lactis). A. Representative histological images of morphologic changes within the periodontal tissues using HE staining of sagittal sections. B. The bar graphs demonstrate the number of inflammatory cells and host 
regenerative periodontal cells per $1.0 \mathrm{~mm} 2$ of connective tissue in the maxillary specimens. In three tissue sections per mouse specimen, the number of inflammatory cells, gingival fibroblasts in connective tissues adjacent to the gingival epithelium, number of periodontal ligament cells, and alveolar bone lining cells were counted within a square field $(100 \times 100 \mu \mathrm{m})$ between first and second molars. Data represent the means \pm standard deviation from 3 mice per group. a, significantly different compared to the control group $(p<0.05)$; $b$, significantly different compared to the infection group ( $<0.05)$
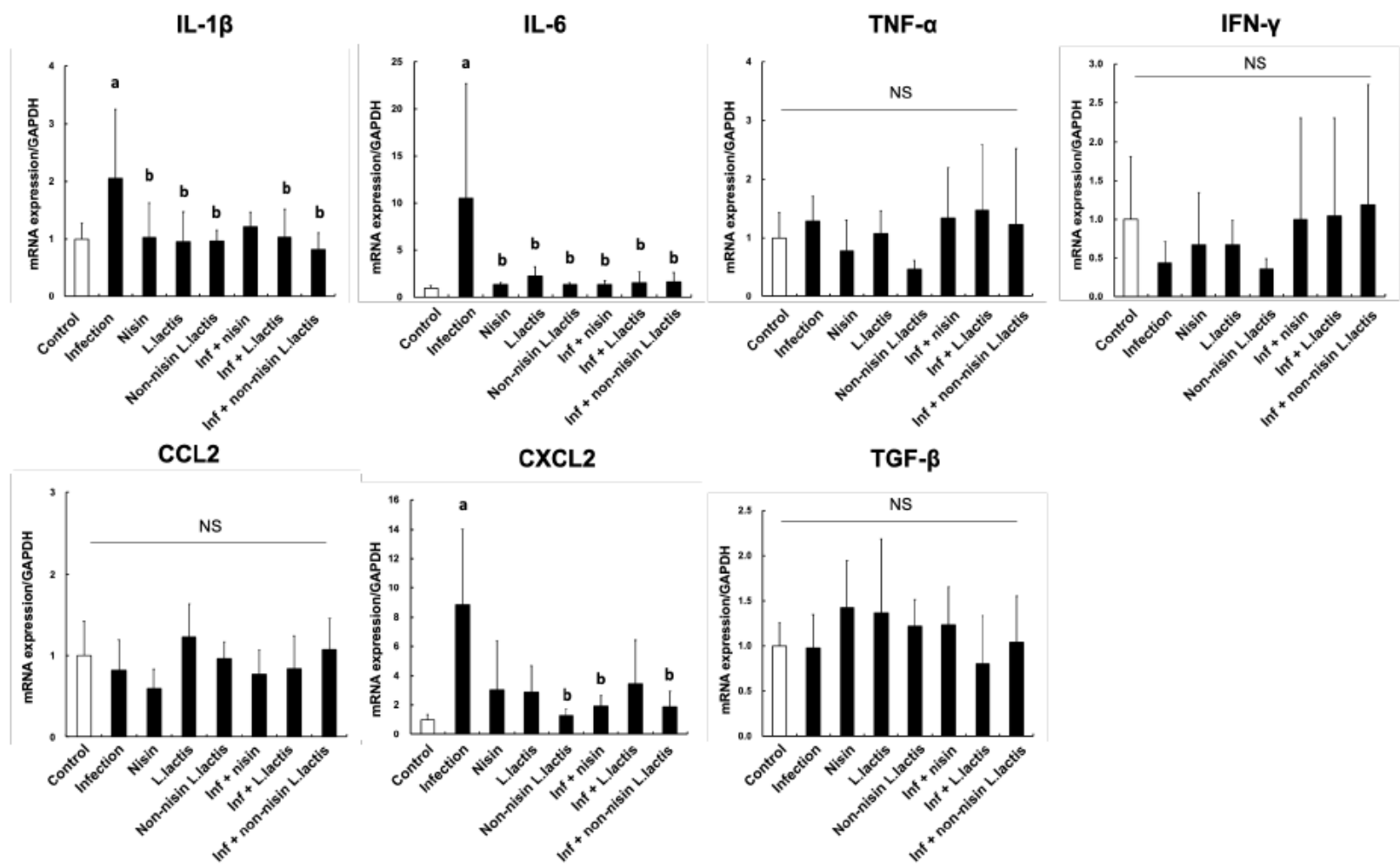

Figure 6

Nisin or nisin-producing probiotic abrogate the host inflammatory cytokine response in gingival tissues. To evaluate the immune cytokine profiles in gingival tissues, mRNA expression of IL-1 $\beta$, IL-6, TNF- $a$, IFN- $\gamma$, CCL2, CXCL2, and TGF- $\beta 1$ were measured by real-time PCR. The amount of mRNA in each reaction was normalized to GAPDH, which is a housekeeping gene. Data are shown as means \pm standard deviation from 6 mice per group. a, $p<0.05$ compared with the Control group. $b, p<0.05$ compared with the Infection group.

A.

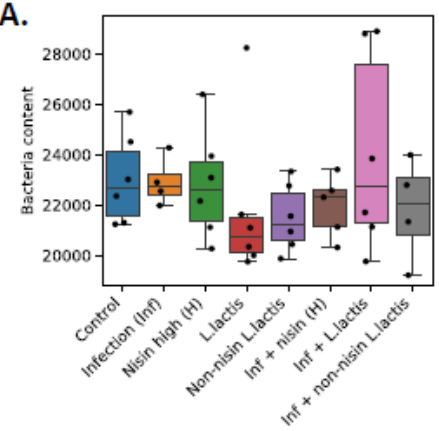

C.

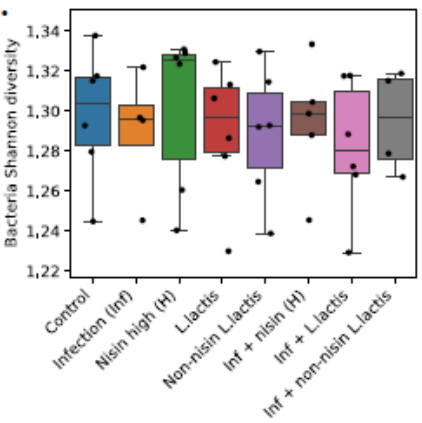

B.

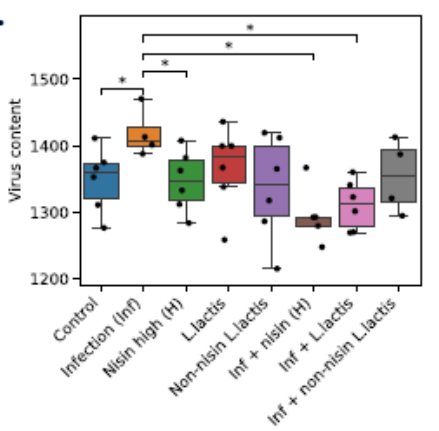

D.

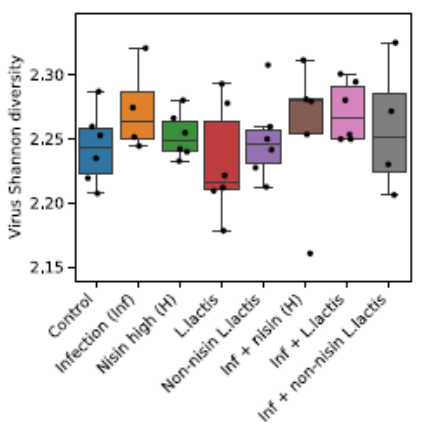

Figure 7 
Comparison of bacterial and viral content and diversity scores across groups show differences in viral content upon infection that shift back with nisin treatment. The groups included Control, Infection, Nisin $(\mathrm{H})$, L. lactis, Non-nisin L. lactis, Infection+Nisin $(\mathrm{H})$, Infection + L. lactis, and Infection + Non-nisin L. lactis). A and B. Bacterial and viral content in TPM and $95 \%$ confidence interval (Cl) is shown across groups. In terms of bacterial content, there is no significant difference between groups. In terms of viral content, the Infection group has significantly higher virus content than the Control group, Nisin group, Infection + Nisin (H) group, and Infection + L. lactis group. C and D. Bacterial and viral Shannon diversity is shown for different groups. In terms of bacterial diversity, there is no significant difference between groups. In terms of viral diversity, the Infection group has slightly higher but non-significant diversity than the Control and L. lactis groups.

A.

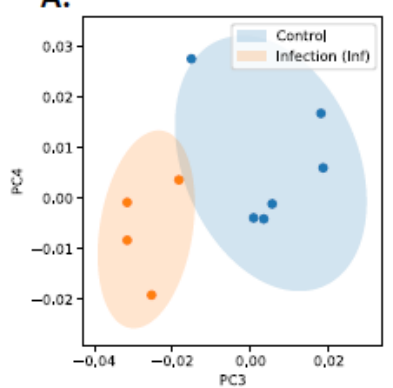

B.

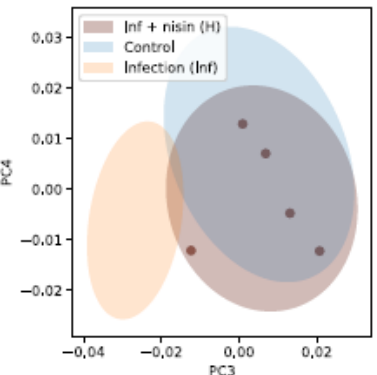

E.

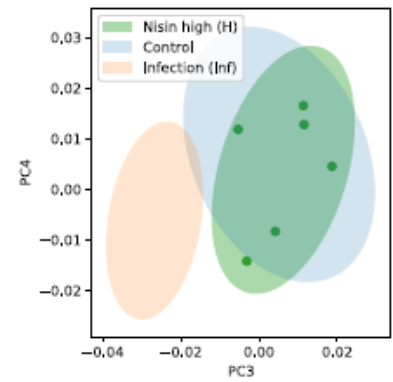

C.

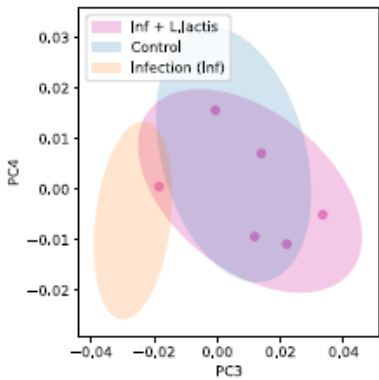

F.

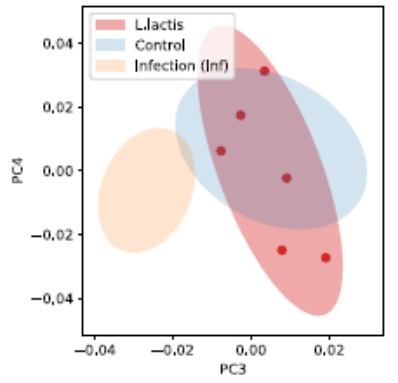

D.

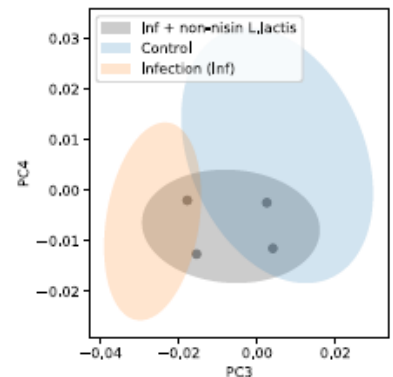

G.

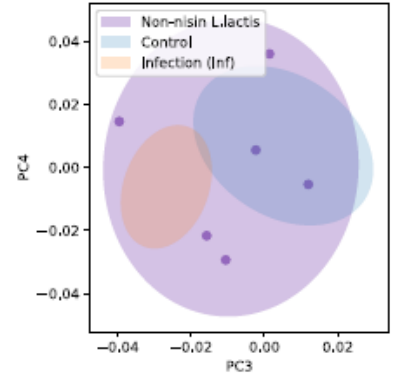

Figure 8

Principal Coordinates Analysis (PCoA) plots for microbiome composition of different groups showing nisin/nisin probiotic shift oral microbiome back toward healthy control levels following infection (Control, Infection, Nisin $(H)$, L. lactis, Non-nisin L. lactis, Infection+Nisin $(H)$, Infection + L. Iactis, Infection + Non-nisin L. lactis). A. PC3 and PC4 separate the Control group from the Infection group. B-G. Overlay each of the other groups on top of Panel A respectively. Among infected groups, those treated with nisin (Panel B) and L. lactis (Panel C) are similar to the Control group, while those treated with non-nisin L. lactis (Panel D) is in the middle of the Control group and the Infection group. Among non-infected groups, those treated with nisin (Panel E) and L. lactis (Panel F) are similar to the Control group, while those treated with non-nisin L. lactis (Panel G) have a very high variance, likely due to poorer sample quality. 

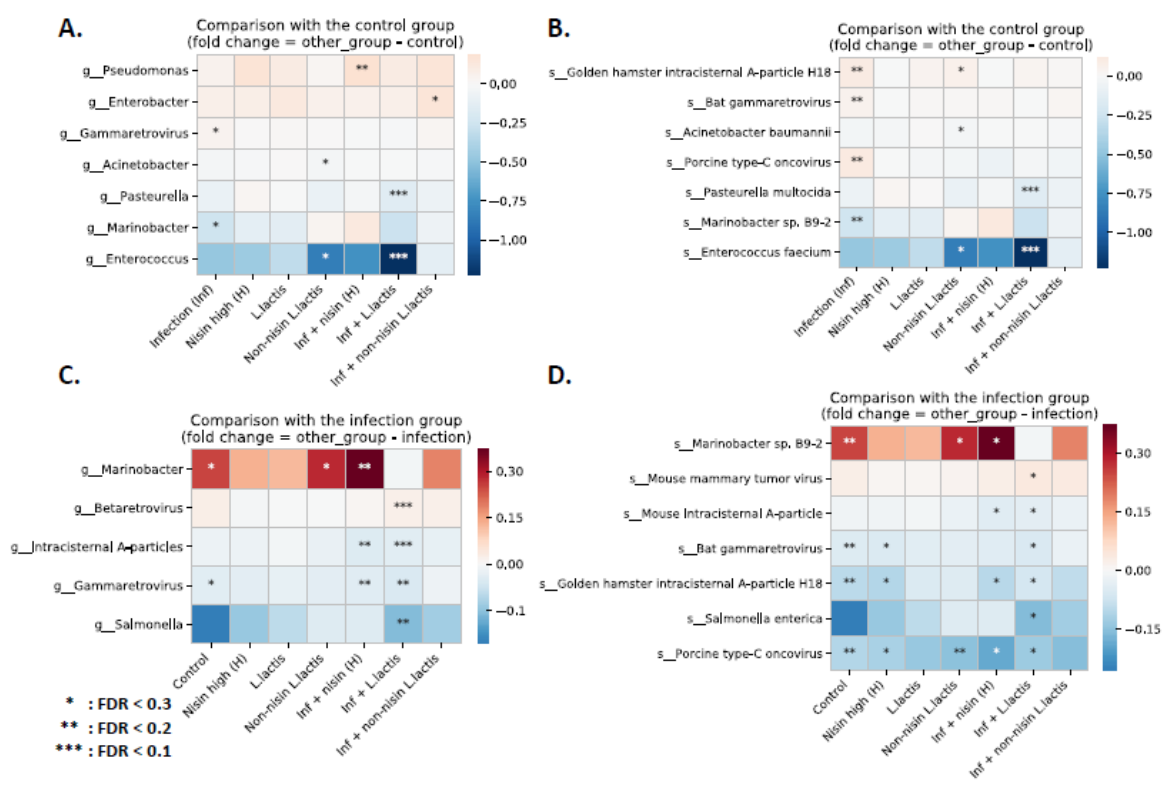

E.

F.

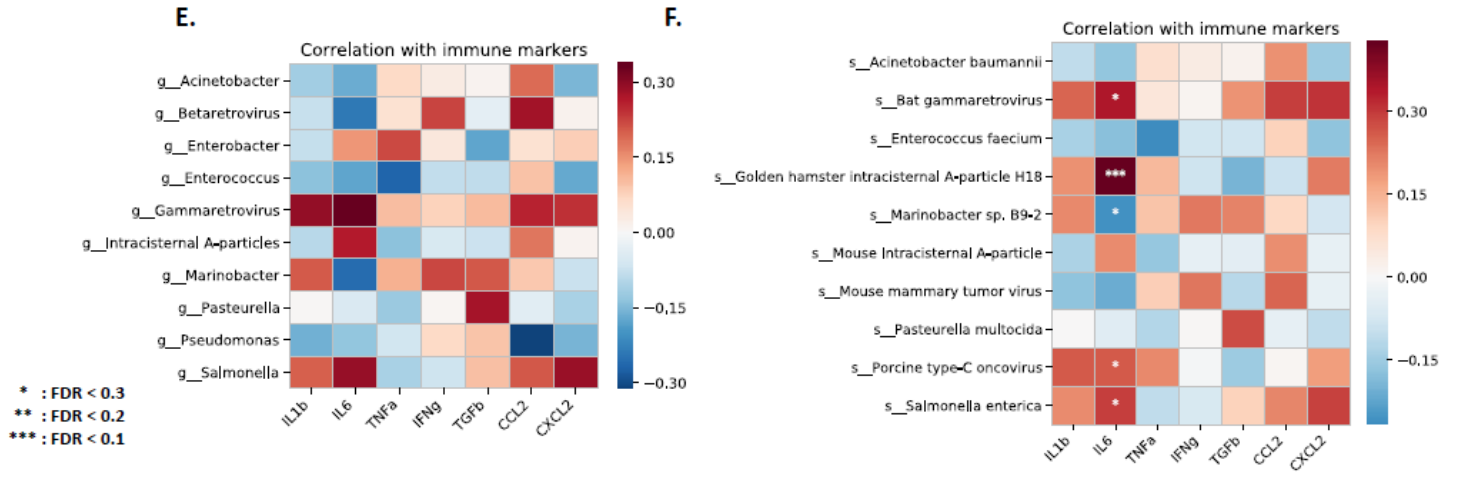

\section{Figure 9}

Differential abundance analysis for bacteria and viruses across groups highlight bacterial and viral members that align with healthy controls and infection and correlate with cytokine levels. The groups included Control, Infection, Nisin (H), L. Lactis, Non-nisin L. lactis, Infection + nisin (H), Infection + L. lactis, and Infection + Non-nisin L. lactis. A. Comparison at genus level between the Control group and other groups. B. Comparison at species level between the Control group and other groups. C. Comparison at genus level between the Infection group and other groups. D. Comparison at species level between the Infection group and other groups. The color represents the fold change against the reference group ( $A$ and $B$; Control group, and $C$ and $D ;$ Infection group). Red color means positive fold change and blue color means negative fold change. Astericks represent the level significant level; $* \star \star F D R<0.1, * \star F D R<0.2, F D R *<0.3$. E and F. A correlation of all significant microbes (genus and species significant in at least one comparison in Figure 9) with immune cytokine levels were computed across all animals. A. Correlation of significant genus members with immune cytokine levels. B. Correlation of significant species members with immune cytokine levels. The color represents the type of correlation (red means positive and blue means negative) and the asterisks represent the level of significance; $\star * * F D R<0.1, * * F D R<0.2, F^{*} R^{\star}<0.3$.

\section{Supplementary Files}

This is a list of supplementary files associated with this preprint. Click to download.

\section{- Figs1.png}

